\title{
The Effect of Si/Al Ratio for Pd/BEA and Pd/SSZ-13 Used as Passive $\mathrm{NO}_{x}$ Adsorbers
}

\author{
Oana Mihai $^{1,2} \cdot$ Lidija Trandafilović $^{1} \cdot$ Travis Wentworth $^{1} \cdot$ Francesc Fluxa Torres $^{1} \cdot$ Louise Olsson $^{1} \mathbb{C}$
}

Published online: 10 July 2018

(c) The Author(s) 2018

\begin{abstract}
The mitigation of cold-start emissions involves the development of passive $\mathrm{NO}_{x}$ adsorbers (PNA) systems that store $\mathrm{NO}_{x}$ at low temperature, being designed to release the trapped $\mathrm{NO}_{x}$ at higher temperatures, where downstream $\mathrm{NO}_{x}$ reduction catalysts are efficient. Pd-based zeolites (BEA, SSZ-13) with different SAR (Si-to-Al ratio) were used for PNA investigation, and $\mathrm{Pd} / \mathrm{Ce} / \mathrm{Al}_{2} \mathrm{O}_{3}$ catalyst was used as a reference for comparison. In this study, $\mathrm{NO}_{x}$ adsorption is investigated at low temperature $\left(80^{\circ} \mathrm{C}\right.$ ) and it is released during a temperature ramp (to $400^{\circ} \mathrm{C}$ ) under various gas feed composition. Moreover, detailed characterization was performed using BET, XRD, XPS, TPO, STEM and ICP-SFMS and the stored NO species was studied using in-situ DRIFTS. The addition of $\mathrm{CO}$ to the storage mixture resulted in that for Pd/zeolites with low and medium SAR the binding energy for NO was increased. In addition, $\mathrm{NO}$ was stored in larger quantities, especially for the $\mathrm{Pd} / \mathrm{SSZ}-13$ samples. However, for Pd/BEA $\left(\mathrm{SAR}=300\right.$ ) no such stable NO species was formed and for $\mathrm{Pd} / \mathrm{Ce} / \mathrm{Al}_{2} \mathrm{O}_{3}$ the $\mathrm{CO}$ addition was even negative. Moreover, in-situ NO DRIFTS showed that there was large amount of nitrosyls on ionic palladium for the $\mathrm{Pd} /$ zeolites with low and medium SAR, indicating that a significant fraction of the palladium was in ionexchanged positions, while this peak was small for the Pd/BEA $(\mathrm{SAR}=300)$ and non-existing for $\mathrm{Pd} / \mathrm{Ce} / \mathrm{Al}_{2} \mathrm{O}_{3}$. Thus, CO addition is beneficial for Pd species that are in ion-exchanged positions, but this is not the case for Pd particles and this can explain the observations that $\mathrm{CO}$ is only beneficial for $\mathrm{Pd} /$ zeolites with low and medium SAR. Moreover, experiments with similar SAR [Pd/BEA $(\mathrm{SAR}=25)$ and Pd/SSZ-13 (SAR =24)], showed that there is larger stability of the stored $\mathrm{NO}_{x}$ in the small pore $\mathrm{Pd} / \mathrm{SSZ}-13$.
\end{abstract}

Keywords Palladium $\cdot \mathrm{Al}_{2} \mathrm{O}_{3} \cdot \mathrm{BEA} \cdot \mathrm{SSZ}-13 \cdot$ Passive $\mathrm{NO}_{x}$ adsorbers $(\mathrm{PNA}) \cdot \mathrm{DRIFTS} \cdot \mathrm{TPD}$

\section{Introduction}

The stringent $\mathrm{NO}_{x}$ emission regulations [1] involve advanced implementation of $\mathrm{NO}_{x}$ reduction techniques, such as $\mathrm{NO}_{x}$-storage reduction (NSR), also referred as Lean $\mathrm{NO}_{x}$ traps (LNT) [2, 3] and selective catalytic reduction (SCR) [4], in order to control the $\mathrm{NO}_{x}$ emissions from lean-burn engines [5, 6]. However, NSR is not efficient at low temperature since $\mathrm{NO}$ oxidation followed by $\mathrm{NO}_{2}$ storage over

Louise Olsson

louise.olsson@chalmers.se

1 Chemical Engineering; Competence Centre for Catalysis, Chalmers University of Technology, 41296 Gothenburg, Sweden

2 Department of Petroleum Processing Engineering and Environmental Protection, Petroleum-Gas University of Ploiesti, 39 Bucuresti Blvd., 100680 Ploiesti, Romania alkaline-earth materials or alkali metals must occur. Also, urea SCR has limitations at low temperatures, where one of the major difficulties is that urea cannot be dosed below ca $200{ }^{\circ} \mathrm{C}$, since it otherwise will form deposits such as e.g. biuret [7]. Due to the low temperature limitations of both the NSR and SCR techniques, the $\mathrm{NO}_{x}$ species released during cold-start cannot be converted. An attractive strategy focused on the storage and reduction of $\mathrm{NO}_{x}$ emissions during cold-start is the so-called passive $\mathrm{NO}_{x}$ adsorber [8, 9] (PNA) technology. In this concept, the $\mathrm{NO}_{x}$ is stored at low temperatures and then thermally released once the SCR system reaches its operating temperature. It is important to release the $\mathrm{NO}_{x}$ above $200{ }^{\circ} \mathrm{C}$, however it is also important that the temperature is not too high, because than there is a risk that the PNA is not properly regenerated. Thus, a release temperature between 200 and $300{ }^{\circ} \mathrm{C}$ seems to be ideal.

In early studies of passive $\mathrm{NO}_{x}$ adsorbers, $\mathrm{Pt} / \mathrm{Al}_{2} \mathrm{O}_{3}[10]$ as well as $\mathrm{Ag} / \mathrm{Al}_{2} \mathrm{O}_{3}[9,11]$ were studied. However, the Pt/ 
$\mathrm{Al}_{2} \mathrm{O}_{3}$ sample releases most of the $\mathrm{NO}_{x}$ below $200{ }^{\circ} \mathrm{C}$ or above $350{ }^{\circ} \mathrm{C}$, which is not in the optimum interval. Moreover, the silver based catalysts required that small amounts of hydrogen was present, which is a limitation [9]. In a patent by Johnson Matthey [12], $\mathrm{Pd}$ and $\mathrm{CeO}_{2}$ containing catalysts showed interesting properties, where $\mathrm{NO}_{x}$ was stored below temperature of $200^{\circ} \mathrm{C}$ and released above this temperature. However, $\mathrm{Pd} / \mathrm{CeO}_{2}$ exhibit low $\mathrm{NO}_{x}$ storage and in addition has large problems with sulfur adsorption [13].

Chen et al. [13] found that $\mathrm{Pd} /$ zeolites were very promising materials for PNA applications. Moreover, Theis and Lambert [14] found that the presence of $\mathrm{C}_{2} \mathrm{H}_{4}$ improved the $\mathrm{NO}_{x}$ storage after thermal aging of the PNA. The zeolite structure plays a key role in the NO adsorption ability on the Pd sites, and Pd on MFI, CHA, and BEA zeolites showed considerable $\mathrm{NO}_{x}$ storage and desorption efficiencies [13]. However, Pd/BEA was better than the other investigated zeolites in terms of $\mathrm{NO}_{x}$ storage at $100{ }^{\circ} \mathrm{C}$ or lower and $\mathrm{NO}_{x}$ release above $200{ }^{\circ} \mathrm{C}$ [13]. Using several characterization techniques Zheng et al. [15] examined Pd/BEA, Pd/ZSM-5 and Pd/SSZ-13 and found that there are multiple Pd species on the $\mathrm{Pd} /$ Zeolites; $\mathrm{Pd}$ in the cationic sites of zeolites and $\mathrm{PdO}_{2}$ and $\mathrm{PdO}$ particles on the external surface. They also concluded that in the small pore zeolites there are more particles on the outside due to sterical hindrance [15]. However, high temperature treatment $\left(750^{\circ} \mathrm{C}\right)$ resulted in an increased amount of atomically dispersed Pd in Pd/ZSM-5 [16]. Moreover, Lee et al. [16] found that the Si/Al loading in ZSM-5 was important for the $\mathrm{NO}$ storage and an optimum of $\mathrm{Si} / \mathrm{Al}$ ratio of 30 was found. $\mathrm{Vu}$ et al. [17] found that the addition of $\mathrm{CO}$ to the feed during NO storage results in an increase in the temperature for $\mathrm{NO}_{x}$ release over Pd/BEA. The effect of CO is to reduce the palladium and metallic $\mathrm{Pd}$, "naked" $\mathrm{Pd}^{2+}$, and $\mathrm{Pd}^{+}$sites are the active sites for $\mathrm{NO}$ adsorption in the presence of CO [15]. Different Pd based zeolites have been examined, and it is clear that different zeolites results in different NO storage and release behavior, where Pd/BEA is the best at low adsorption temperature and Pd/SSZ-13 at higher temperatures [15]. Moreover, for Pd/ZSM-5 it is also found that the $\mathrm{Si} / \mathrm{Al}$ ratio is critical in PNA experiments without $\mathrm{CO}$ presence [16]. However, there are to our knowledge, no studies available where the effect of $\mathrm{Si} / \mathrm{Al}$ ratio on $\mathrm{Pd} /$ BEA and Pd/SSZ-13 is studied. Moreover, there are no studies presented where the effect of $\mathrm{Si} / \mathrm{Al}$ ratio on $\mathrm{Pd} /$ zeolites are examined in the presence of $\mathrm{CO}$, which is significantly changing the adsorption and desorption characteristics [15].

The objective of the present work is therefore to study the effect of different $\mathrm{Si} / \mathrm{Al}$ ratio on the Pd/BEA and $\mathrm{Pd} /$ SSZ-13, with and without the presence of CO. This is done through NO temperature desorption (TPD) experiments in various gas mixtures. The catalysts are thoroughly characterized using BET, ICP-SFMS, XRD, TPO, STEM, XPS and in-situ DRIFT spectroscopy to study the adsorbed NO species. In addition, a $\mathrm{Pd} / \mathrm{Ce} / \mathrm{Al}_{2} \mathrm{O}_{3}$ catalyst was examined as a reference sample.

\section{Experimental}

\subsection{Catalyst Synthesis}

\subsubsection{Pd/Ce/Al $\mathrm{O}_{3}$ as a Reference Sample}

A $1 \% \mathrm{Pd} / 8 \% \mathrm{Ce} / \mathrm{Al}_{2} \mathrm{O}_{3}$ catalyst was prepared as a reference material. The $\gamma-\mathrm{Al}_{2} \mathrm{O}_{3}$ (Puralox SBa-200, Sasol, pre-calcined at $750{ }^{\circ} \mathrm{C}$, for $2.5 \mathrm{~h}, 4^{\circ} \mathrm{C} / \mathrm{min}$ ), an aqueous solution of $\mathrm{Pd}\left(\mathrm{NO}_{3}\right)_{2}$ (Heraeus $\mathrm{GmbH}, 16.37 \mathrm{wt} \% \mathrm{Pd}$ ) and Cerium(III) nitrate hexahydrate (Sigma Aldrich) were used as starting materials. The desired amount of Cerium(III) nitrate hexahydrate, corresponding to $8 \mathrm{wt} \%$ Ce was loaded in two steps (each of $4 \mathrm{wt} \% \mathrm{Ce}$ ) by incipient wetness impregnation method, with drying between each step. The Ce nitrate was dissolved in purified deionized "MilliQ" water (Millipore) and the aqueous solution was dropwise added to the alumina support. After the sample was dried at $100{ }^{\circ} \mathrm{C}$ overnight and calcined at $500{ }^{\circ} \mathrm{C}$ for $5 \mathrm{~h}$, a corresponding amount of $\mathrm{Pd}$ precursor (to reach $1 \mathrm{wt} \%$ ) was dissolved in an appropriate amount of "MilliQ" water and was impregnated on the $\mathrm{Ce} / \mathrm{Al}_{2} \mathrm{O}_{3}$. After the addition of the Pd solution, the resulting powder was dried and calcined at same conditions as described above.

\subsubsection{Pd/SSZ-13}

The hydrothermal synthesis of Na-SSZ-13 was performed based on the method described by McEwen et al. [18]. Starting materials used for the synthesis was sodium silicate solution (Sigma-Aldrich), TMAAI 25\% solution of tricyclo [3.3.1.13, 7] decan-1-aminium, $N, N, N$-trimethyl-hydroxide (Sachem, ZeoGen SDA), zeolite Y CBV712 (Zeolyst International) and $\mathrm{NaOH}$ (Sigma-Aldrich). The obtained Nazeolite sample was calcined at $550^{\circ} \mathrm{C}$ for $8 \mathrm{~h}$ with a ramp of $0.5^{\circ} \mathrm{C} / \mathrm{min}$. In the next step, $\mathrm{Na}$-SSZ-13 was ion-exchanged with $\mathrm{NH}_{4} \mathrm{NO}_{3}$, following a detailed procedure described by Olsson et al. [19]. The H-form of SSZ-13 was obtained by calcination of $\mathrm{NH}_{4}$-form in air for $4 \mathrm{~h}$ at $550{ }^{\circ} \mathrm{C}$ with a ramp rate of $5{ }^{\circ} \mathrm{C} \mathrm{min}^{-1}$. The $\mathrm{Pd} / \mathrm{SSZ}-13$ was synthesized using incipient wetness impregnation with the appropriate amounts of Pd precursors corresponding to $1 \mathrm{wt} \% \mathrm{Pd}$. After the Pd solution had been added, the resulting powder was dried at $100{ }^{\circ} \mathrm{C}$ overnight and calcined at $500{ }^{\circ} \mathrm{C}$ for $5 \mathrm{~h}$ with $2{ }^{\circ} \mathrm{C} / \mathrm{min}$.

Moreover, in order to prepare a SSZ-13 with higher SAR $\left(\mathrm{SiO}_{2} / \mathrm{Al}_{2} \mathrm{O}_{3}\right)$ ratio was instead zeolite Y CBV780 (Zeolyst International) used as starting material. $\mathrm{NH}_{4^{-}}$and $\mathrm{H}-$ and 
Pd- forms of SSZ-13 were prepared using the same procedure as described in previous paragraph.

\subsection{3 $\mathrm{Pd} / \mathrm{BEA}$}

Beta zeolite (CP814E, SAR 25; CP814C, SAR 38, and CP 811-300, SAR 300, Zeolyst International) were used as support for impregnation of $\mathrm{Pd}$ precursor. Same procedure as mentioned in Sect. 2.1.2 was followed for the synthesis. For simplification, the catalysts used in this work are summarized in Table 1.

\subsection{Monolith Preparation}

The monoliths were cut from a commercial honeycomb cordierite structure $(20 \mathrm{~mm}$ in length, $21 \mathrm{~mm}$ in diameter, $400 \mathrm{cpsi}$ ) and then heated to $500{ }^{\circ} \mathrm{C}$ for $2 \mathrm{~h}$. The monolith substrates were coated using slurry consisting of $20 \mathrm{wt} \%$ solid phase and a liquid phase of ethanol and water (1:1). The catalyst and Disperal P2 (boehmite binder) ratio in the solid phase was 95:5 based on weight. Each time after dipping the monolith, the excess slurry was removed and the monolith dried in air for $2 \mathrm{~min}$ at $90{ }^{\circ} \mathrm{C}$. The procedure was repeated several times until the desired amount of washcoat ( $\sim 750 \mathrm{mg}$ ) was reached after which the monoliths were calcined in air at $500{ }^{\circ} \mathrm{C}$ for $5 \mathrm{~h}, 2^{\circ} \mathrm{C} / \mathrm{min}$ ramp.

\subsection{Catalyst Characterization}

The BET surface area and pore volume were determined by measuring $\mathrm{N}_{2}$ adsorption isotherms at the temperature of liquid $\mathrm{N}_{2}\left(-195^{\circ} \mathrm{C}\right)$ using a Tristar 3000 (Micromeritics) instrument. Prior to the measurement, the samples were degassed at $220{ }^{\circ} \mathrm{C}$ for $3 \mathrm{~h}$ under vacuum.

Elemental analysis was used for determining the $\mathrm{Si} / \mathrm{Al}$ ratio of the SSZ-13 samples. This was done by inductively coupled plasma sector field mass spectrometer (ICP-SFMS) and the measurements were performed by ALS Scandinavia AB.

Table 1 Summary of prepared catalysts

\begin{tabular}{lllll}
\hline Catalyst type & Support & $\begin{array}{l}\mathrm{SAR}\left(\mathrm{SiO}_{2} / \mathrm{Al}_{2} \mathrm{O}_{3}\right. \\
\text { ratio })\end{array}$ & $\begin{array}{l}\text { Metal load- } \\
\text { ings (wt } \%)\end{array}$ \\
\cline { 3 - 5 } & & & $\mathrm{Pd}$ & $\mathrm{Ce}$ \\
\hline $\mathrm{Pd} / \mathrm{Ce} / \mathrm{Al}_{2} \mathrm{O}_{3}$ & $\gamma-\mathrm{Al}_{2} \mathrm{O}_{3}$ & - & 1 & 8 \\
$\mathrm{Pd} / \mathrm{SSZ}-13$ & $\mathrm{SSZ}-13$ & 12 & & - \\
$\mathrm{Pd} / \mathrm{BEA}$ & $\mathrm{BEA}$ & 24 & & \\
& & 38 & & \\
& & 300 & & \\
& & 38 & & \\
\end{tabular}

XRD was performed using a powder diffractometer (BrukerAXS D8 advance) with $\mathrm{Cu} \mathrm{K} \alpha$ source $(\lambda=1.542 \AA)$ operating at $40 \mathrm{kV}$ and $40 \mathrm{~mA}$.

X-ray photoelectron spectroscopy (XPS) measurements were done on a Perkin Elmer PHI 5000C ESCA system equipped with a monochromatic $\mathrm{Al} \mathrm{K}$ X-ray source with a binding energy of $1486.6 \mathrm{eV}$. All binding energies were referenced to a $\mathrm{C} 2 \mathrm{~s} \mathrm{BE}$ of $284.8 \mathrm{eV}$. Note that the samples experienced variable degrees of charging and a neutralizer with emission control (21.8) was therefore used to minimize this charging. PdO from Sigma Aldrich (99.97\% trace metals basis) were used as reference material.

A transmission electron microscopy (TEM) analysis was performed to examine the Pd particle size for fresh samples and samples scraped from monoliths after flow reactor experiments. The powder of the sample was placed on carbon films using TEM Cu grids. The particles were imaged using an FEI Titan 80-300 microscope equipped with a field emission gun (FEG), a probe Cs (spherical aberration) corrector and a Gatan image filter (GIF) (Tridium) operated at an acceleration voltage of $300 \mathrm{kV}$. The images were recorded using a high angle annular dark field (HAADF) detector in the scanning TEM imaging mode (STEM).

\subsection{Flow Reactor Experiments}

\subsubsection{Temperature-Programmed Desorption (TPD) Experiments}

The TPD experiments were performed in a flow reactor setup. It consisted of a horizontal quartz tube $(70 \mathrm{~cm}$ length, $22 \mathrm{~cm}$ inner diameter), gas dosing system using several mass flow controllers (MFC, Bronkhorst), an evaporation mixing system for controlling water vapor flow (CEM, Bronkhorst) into which the monolith was inserted. Two type-K thermocouples were used to measure the temperature in the gas flow before the catalyst and in the center of the middle channel. A gas Fourier transform infrared (FTIR) spectrometer (MKS Multigas 2030) was connected to the outlet of the reactor for monitoring the concentrations of the gases. The lines prior to and after the reactor were heated to $200{ }^{\circ} \mathrm{C}$ and insulated in order to prevent water condensation during measurements. Argon was used as inert balance gas. The total flow was $750 \mathrm{ml} \mathrm{min}{ }^{-1}$ during the TPD experiments, whereas a flow of $3300 \mathrm{ml} \mathrm{min}{ }^{-1}$ was employed for pretreatment of the samples.

In this study, several TPD procedures were applied (marked as TPD 1, TPD 2, etc.), as listed in Table 2. In order to obtain stable activity, the catalysts were first degreened using 500 ppm NO, $5 \% \mathrm{CO}_{2}, 8 \% \mathrm{O}_{2}$ and $5 \% \mathrm{H}_{2} \mathrm{O}$ at $500{ }^{\circ} \mathrm{C}$ for $1 \mathrm{~h}$ with the total flow of $3500 \mathrm{ml} \mathrm{min}^{-1}$. Prior to each TPD experiment the catalyst was pre-treated at $400{ }^{\circ} \mathrm{C}$, using the following three sequences: (1) $1 \% \mathrm{H}_{2}, 5 \% \mathrm{CO}_{2}$ and $5 \%$ 
Table 2 Experimental procedure for TPD experiments

\begin{tabular}{|c|c|c|c|c|}
\hline \multirow[t]{2}{*}{$\mathrm{TPD}^{\mathrm{a}}$} & \multicolumn{2}{|l|}{ Adsorption } & \multicolumn{2}{|l|}{ Desorption } \\
\hline & Gas composition & Temperature $\left({ }^{\circ} \mathrm{C}\right) /$ time $(\min )$ & Isothermal, $80^{\circ} \mathrm{C}$, for $15 \mathrm{~min}$ & Ramp to $400^{\circ} \mathrm{C}, 20^{\circ} \mathrm{C} / \mathrm{min}$ \\
\hline 1 & $\mathrm{NO}+\mathrm{O}_{2}$ & $80 / 30$ & $\mathrm{O}_{2}+\mathrm{Ar}$ & \\
\hline 2 & $\mathrm{NO}+\mathrm{O}_{2}+\mathrm{H}_{2} \mathrm{O}$ & & $\mathrm{O}_{2}+\mathrm{H}_{2} \mathrm{O}+\mathrm{Ar}$ & \\
\hline 3 & $\mathrm{NO}+\mathrm{O}_{2}+\mathrm{H}_{2} \mathrm{O}+\mathrm{CO}_{2}$ & & $\mathrm{O}_{2}+\mathrm{H}_{2} \mathrm{O}+\mathrm{CO}_{2}+\mathrm{Ar}$ & \\
\hline 4 & $\mathrm{NO}+\mathrm{O}_{2}+\mathrm{H}_{2} \mathrm{O}+\mathrm{CO}_{2}+\mathrm{CO}$ & & $\mathrm{O}_{2}+\mathrm{H}_{2} \mathrm{O}+\mathrm{CO}_{2}+\mathrm{Ar}$ & \\
\hline
\end{tabular}

${ }^{\mathrm{a}}$ The $\mathrm{NO}, \mathrm{O}_{2}, \mathrm{CO}_{2}, \mathrm{CO}$ and $\mathrm{H}_{2} \mathrm{O}$ were present in the concentrations of $200 \mathrm{ppm}, 8 \%, 5 \%, 400 \mathrm{ppm}$ and 5\%, respectively in all TPD tests

$\mathrm{H}_{2} \mathrm{O}$ for $15 \mathrm{~min}$; (2) $5 \% \mathrm{CO}_{2}$ and $5 \% \mathrm{H}_{2} \mathrm{O}$ for $5 \mathrm{~min}$; (3) $5 \%$ $\mathrm{CO}_{2}, 8 \% \mathrm{O}_{2}$ and $5 \% \mathrm{H}_{2} \mathrm{O}$ for $20 \mathrm{~min}$. After pretreatment, the samples were cooled to the target temperature $\left(80^{\circ} \mathrm{C}\right)$ under $\left(\mathrm{O}_{2}+\mathrm{Ar}\right)$ for TPD1, $\left(\mathrm{O}_{2}+\mathrm{H}_{2} \mathrm{O}+\mathrm{Ar}\right)$ for TPD2, $\left(\mathrm{O}_{2}+\mathrm{CO}_{2}+\mathrm{H}_{2} \mathrm{O}+\mathrm{Ar}\right)$ for TPD3 and TPD4. The TPD procedure consisted of an adsorption of $200 \mathrm{ppm}$ NO in the presence of $\mathrm{O}_{2}, \mathrm{H}_{2} \mathrm{O}, \mathrm{CO}_{2}$ and $\mathrm{CO}$ (see Table 2 for details) with an Argon balance at $80{ }^{\circ} \mathrm{C}$ for $30 \mathrm{~min}$. Thereafter, at the same temperature as the adsorption step, the catalyst was flushed with a specific gas mixture for each TPD (see Table 2) for $15 \mathrm{~min}$ to remove loosely bound species from the surface. The temperature was then linearly increased to $400{ }^{\circ} \mathrm{C}$ at a ramp speed of $20{ }^{\circ} \mathrm{C} \mathrm{min}{ }^{-1}$ and finally, the temperature was kept at $400{ }^{\circ} \mathrm{C}$ for $10 \mathrm{~min}$.

\subsubsection{Temperature-Programmed Oxidation (TPO) Experiments}

TPO experiments were conducted in a Setaram Sensys DSC (Digital Scanning Calorimeter) using Ar as the inert balance. About $60 \mathrm{mg}$ of the powder sample was loaded in the quartz tube reactor (inner diameter of $5 \mathrm{~mm}$ ), which was mounted in an electrical furnace as part of calorimeter. In order to pretreat the catalytic surface, the samples were first reduced for $30 \mathrm{~min}$ at $500{ }^{\circ} \mathrm{C}$ in $1 \% \mathrm{H}_{2}$ and subsequently cooled down to $100{ }^{\circ} \mathrm{C}$ in the same reducing atmosphere. After the catalysts were flushed with Ar for $25 \mathrm{~min}$ at $100{ }^{\circ} \mathrm{C}$, the TPO tests were started when $500 \mathrm{ppm} \mathrm{O}_{2}$ was introduced into the system and the catalysts were flushed with $500 \mathrm{ppm} \mathrm{O}_{2}$ for $90 \mathrm{~min}$. Thereafter, oxidation was carried out by heating the samples from 100 to $800{ }^{\circ} \mathrm{C}$ (with a ramp rate of $20^{\circ} \mathrm{C} / \mathrm{min}$ ), while exposing the samples to $500 \mathrm{ppm} \mathrm{O}_{2}$ in Ar. When the temperature reached $800{ }^{\circ} \mathrm{C}$, the catalysts were kept for $60 \mathrm{~min}$ in $\mathrm{O}_{2}$ atmosphere and then the system was cooled down to room temperature in the same environment.

\subsection{In-situ DRIFT Spectroscopy}

The surface species on the samples were characterized during NO adsorption conditions by in-situ DRIFT spectroscopy. The measurements were performed using a Bruker Vertex 70 FTIR spectrometer equipped with a high-temperature reaction cell (Harrick Scientific). Approximately $70 \mathrm{mg}$ of catalyst powder was placed on a porous grid in the sample cup. The sample was covered by a dome equipped with two $\mathrm{KBr}$ windows, and reactant gases were flown through the sample using Bronkhorst mass flow controllers. After placing the samples in the reaction cell, each sample was degreened at $550{ }^{\circ} \mathrm{C}$ for $1 \mathrm{~h}$ in $8 \% \mathrm{O}_{2}, 1000 \mathrm{ppm}$ $\mathrm{NO}$ and $1 \% \mathrm{H}_{2} \mathrm{O}$. After degreening, the samples were pretreated at same temperature in $8 \% \mathrm{O}_{2}$ and $1 \% \mathrm{H}_{2} \mathrm{O}$ for $30 \mathrm{~min}$ and then cooled down to $80^{\circ} \mathrm{C}$ in same atmosphere. At this temperature, a background was first acquired under $8 \% \mathrm{O}_{2}$ and $1 \% \mathrm{H}_{2} \mathrm{O}$, Ar balanced. After taking background, $1000 \mathrm{ppm} \mathrm{NO}$ was introduced in the flow in the presence of $8 \% \mathrm{O}_{2}$ and $1 \% \mathrm{H}_{2} \mathrm{O}$ for $30 \mathrm{~min}$. A resolution of $4 \mathrm{~cm}^{-1}$ was adapted and the data are presented as absorbance $(\log \mathrm{I} / \mathrm{R})$.

\section{Results and Discussion}

\subsection{Catalyst Characterization}

The $\mathrm{SiO}_{2} / \mathrm{Al}_{2} \mathrm{O}_{3}$ ratios, denoted $\mathrm{SAR}$, for the synthesized SSZ-13 materials were determined using ICP-SFMS, which resulted in SAR of 12 and 24, respectively. Moreover, the $\mathrm{Na}$ content was below detection limit in the samples. In addition, BET surface areas were measured and resulted in 167.3, 624.6, 669,7, 582.9 and 579.5 for $\mathrm{Pd} / \mathrm{Ce} / \mathrm{Al}_{2} \mathrm{O}_{3}, \mathrm{Pd} /$ SSZ-13 (SAR = 12 and 24) and Pd/BEA (SAR 38 and 300), respectively. According to $\mathrm{N}_{2}$ physisorption data, it can be seen that the BET surface area of the $\mathrm{Pd} / \mathrm{Ce} / \mathrm{Al}_{2} \mathrm{O}_{3}$ catalyst was lower [20], which is expected since alumina support has lower surface area compared to zeolites in general. Highest BET specific surface areas are revealed for small-pore-sized SSZ-13-based materials [21].

Figure 1 shows the diffraction patterns of the calcined zeolite catalysts. Analysis of XRD patterns recorded for the zeolite materials presented in Fig. 1 clearly show the structures of the SSZ-13 [22] (Fig. 1a) and BEA [23, 24] (Fig. 1b). In the case of Pd/SSZ-13 (Fig. 1a), it showed the characteristic of CHA topology with the diffraction peaks matching well with the standard diffraction of zeolite SSZ13 from (1 00 ), ( $\left.\begin{array}{lll}1 & 0 & -1\end{array}\right),\left(\begin{array}{lll}-1 & 1 & -1\end{array}\right),\left(\begin{array}{lll}1 & 1 & 1\end{array}\right),\left(\begin{array}{lll}1 & 0 & -2\end{array}\right),\left(\begin{array}{l}0 \\ 0\end{array}\right.$ 
Fig. 1 XRD patterns of a $\mathrm{Pd} /$ SSZ-13 with SAR $\left(\mathrm{SiO}_{2} / \mathrm{Al}_{2} \mathrm{O}_{3}\right)$ of 12 and 24; $\mathbf{b} \mathrm{Pd} / \mathrm{BEA}$ with SAR of 38 and 300

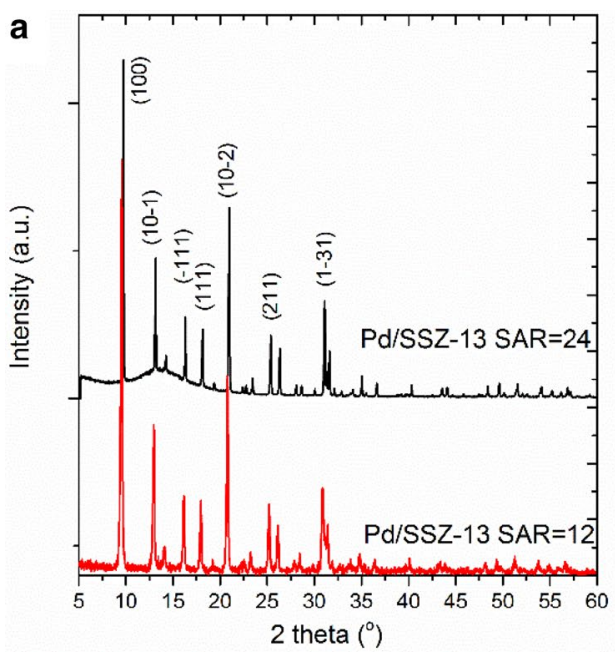

-2 2), ( $\left.\begin{array}{lll}1 & -3 & 1\end{array}\right)$ and (3 10 ) crystal [25, 26]. While the Pd/ BEA (SAR 38 and 300) diffraction peaks are identified as (004), (302) and (304) [27]. As it can be seen from Fig. 1 changing of SAR in zeolite structure did not cause any significant changes of the position of the peaks.

The morphology of the calcined Pd/BEA $(\mathrm{SAR}=300)$ and Pd/SSZ-13 (SAR = 24) was investigated by TEM and the HAADF-STEM micrographs at various magnifications are shown in Fig. 2. Palladium particles can be seen as bright spots and it is clear that the Pd/BEA (SAR=300) shows many and quite large Pd particles (Fig. 2a). This is expected since the SAR ratio is very high; there is only few ionexchange positions available, which results in $\mathrm{Pd}$ particles. Figure $2 b$ presents STEM images of Pd/SSZ-13 (SAR=24).
Also, for $\mathrm{Pd} / \mathrm{SSZ}-13$ it is clear that there are $\mathrm{Pd}$ particles available on the surface, however they are significantly smaller. The size of Pd particles for Pd/BEA (SAR =300) are in the range from 24 till $51 \mathrm{~nm}$, while for $\mathrm{Pd} / \mathrm{SZZ}-13$ $(\mathrm{SAR}=24)$ particle size have range from 1.7 till $5 \mathrm{~nm}$ with the majority of particles size around $2-3 \mathrm{~nm}$. The size differences between Pd/BEA $(\mathrm{SAR}=300)$ and Pd/SSZ-13 $(\mathrm{SAR}=24)$ are probably due to the different SAR. Smaller SAR of $\mathrm{Pd} / \mathrm{SSZ}-13$ is giving more ion-exchanged positions which results in more well dispersed Pd species (Fig. 2).

The effect of running of flow reactor experiments on the $\mathrm{Pd}$ particles size's for $\mathrm{Pd} / \mathrm{BEA}(\mathrm{SAR}=300)$ is examined. In Fig. 3, the results from scrapped of catalysts from used monolith are shown, with $\mathrm{M}$ denoting sample taken from

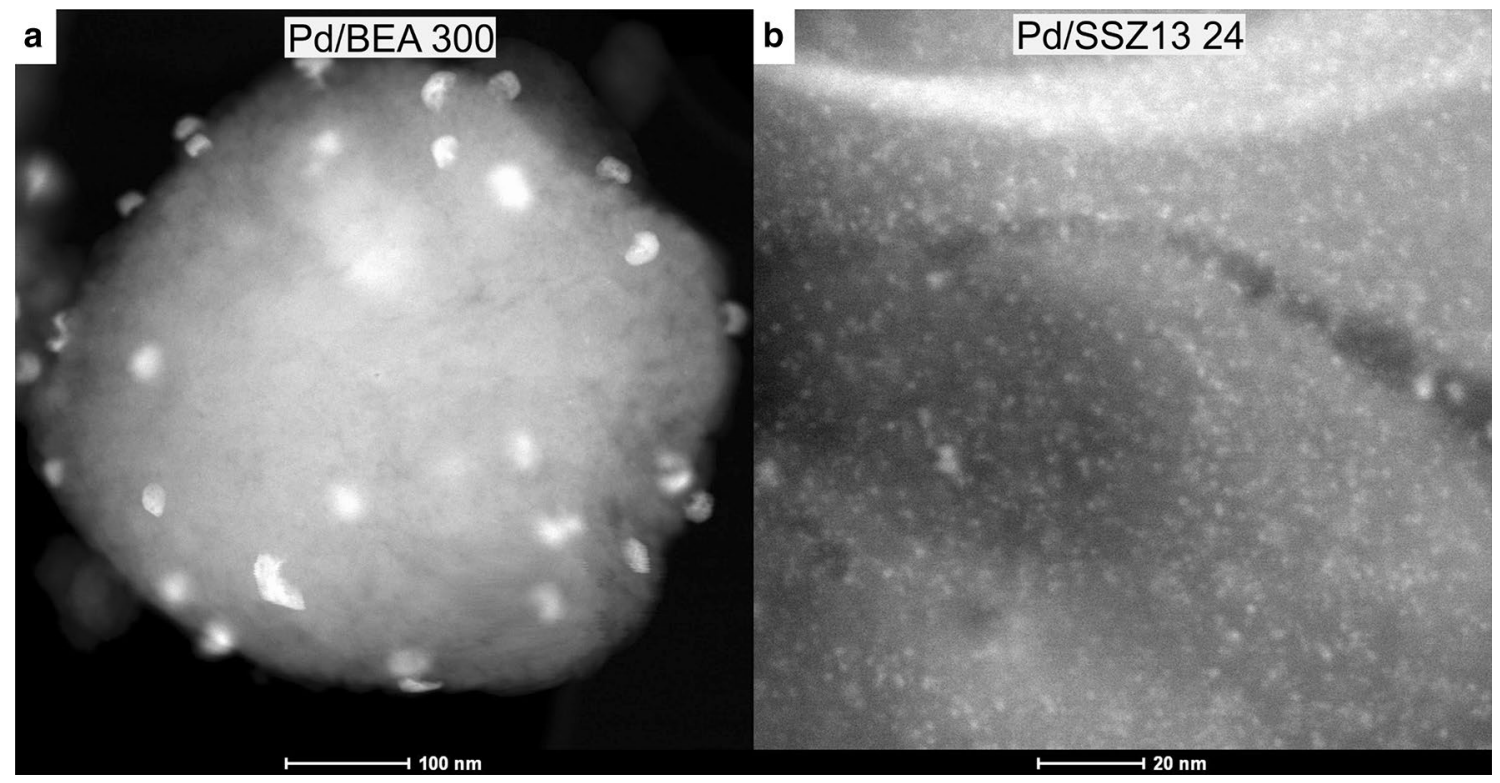

Fig. 2 a STEM images of the Pd/BEA $(\mathrm{SAR}=300)$ at $100 \mathrm{~nm}$; b STEM images of Pd/ SSZ-13 $(\mathrm{SAR}=24)$ at $20 \mathrm{~nm}$ 


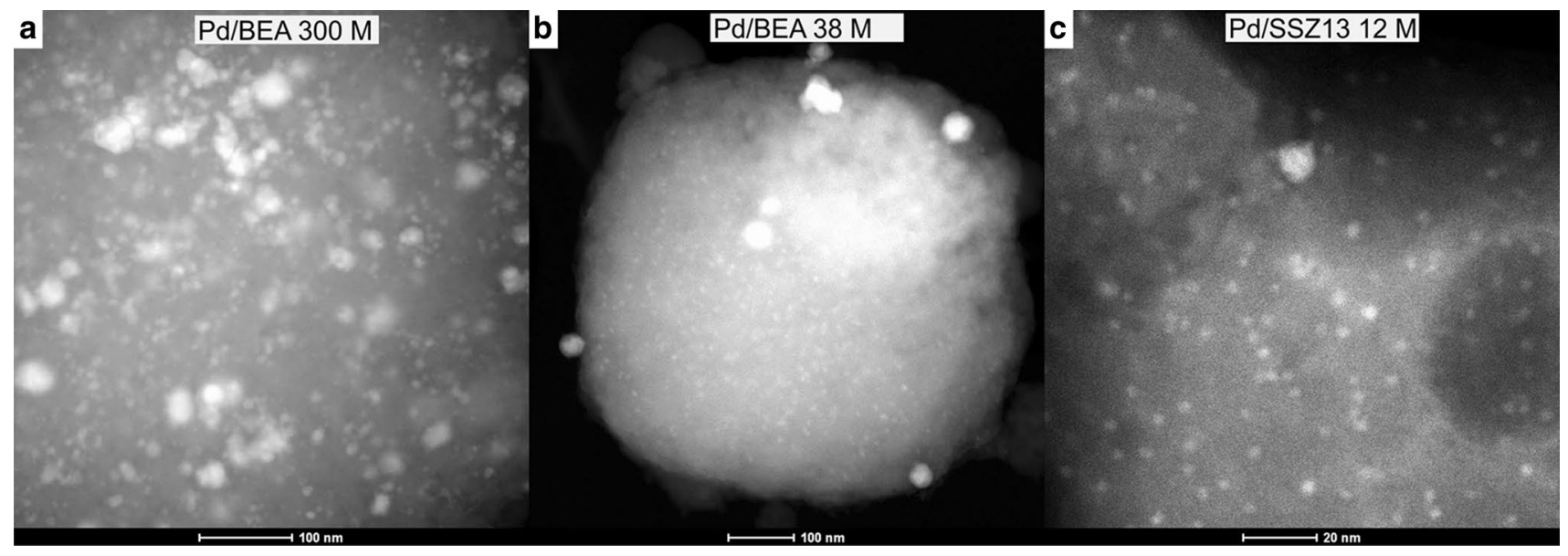

Fig. 3 a STEM images of the Pd/BEA $(\mathrm{SAR}=300)$ at $100 \mathrm{~nm} ; \mathbf{b} \mathrm{Pd} / \mathrm{BEA}(\mathrm{SAR}=38)$ at $100 \mathrm{~nm}$ and $\mathbf{c} \mathrm{Pd} / \mathrm{SSZ}-13(\mathrm{SAR}=12)$ at $20 \mathrm{~nm}$. Scrapped off powder from used monoliths are used

monoliths. As it can be seen from Fig. 3a Pd particles for Pd/BEA ( $\mathrm{SAR}=300$ ) $\mathrm{M}$ are now more dispersed with size ranging from 8 till $40 \mathrm{~nm}$. These results were found on several images on different positions. These results indicate that during flow reactor experiments of Pd/BEA $(\mathrm{SAR}=300)$ the Pd dispersion improved, and this is similar as found for solid state ion-exchange of $\mathrm{Cu} / \mathrm{SAPO}-$ 34 [28]. In the case of Pd/BEA (SAR = 38) M the size of a particles are from the 11 till $14 \mathrm{~nm}$ with quite even distribution. Comparing the particle sizes for Pd/BEA $(\mathrm{SAR}=38) \mathrm{M}$ and $\mathrm{Pd} / \mathrm{BEA}(\mathrm{SAR}=300) \mathrm{M}$ we can see that lower SAR gives the smaller particles. For Pd/SSZ-13 $(\mathrm{SAR}=12) \mathrm{M}$ the particles size is in the range from 2 till $5 \mathrm{~nm}$ (see Fig. 3c), which is similar to the size range fresh $\mathrm{Pd} / \mathrm{SSZ}-13$ (SAR $=24$, presented in Fig. 2b) leading to conclusion that particles are not drastically influenced by SAR and experimental treatment in the case of Pd/SSZ-13 samples.
The oxidative properties of the prepared samples were investigated through TPO tests and the obtained results are shown in Fig. 4. In case of $\mathrm{Pd} / \mathrm{Ce} / \mathrm{Al}_{2} \mathrm{O}_{3}$, the oxidation started at about $120{ }^{\circ} \mathrm{C}$, with the maximum oxygen consumption peak at $301{ }^{\circ} \mathrm{C}$. This behavior is related with the $\mathrm{Pd}$ oxidation to $\mathrm{PdO}$ and ceria oxidation, and is similar to the max adsorption temperature $\left(359^{\circ} \mathrm{C}\right)$ that was obtained on $\mathrm{Pt} / \mathrm{Pd} / \mathrm{Ce} / \mathrm{Al}_{2} \mathrm{O}_{3}$ by Sadokhina et al. [29]. Moreover, at high temperature an oxygen release is visible with a peak maximum at $768{ }^{\circ} \mathrm{C}$, which is due to palladium oxide decomposition.

For all $\mathrm{Pd}$ /zeolites the oxidation occurs at higher temperature compared to the $\mathrm{Pd} / \mathrm{Ce} / \mathrm{Al}_{2} \mathrm{O}_{3}$ sample. The $\mathrm{Pd} / \mathrm{BEA}$ $(\mathrm{SAR}=38)$ and $\mathrm{Pd} / \mathrm{BEA}(\mathrm{SAR}=25)$ have similar oxygen uptake profiles, with maximum around $401^{\circ} \mathrm{C}$ (see Fig. 4a). Interestingly, the Pd/BEA with the higher SAR (SAR = 38) released oxygen, indicating decomposition of palladium oxides, while Pd/BEA (SAR = 25) did not. In Fig. 4b, the Pd/
Fig. 4 TPO tests over a Pd/ $\mathrm{BEA}(\mathrm{SAR}=25$ and 38$)$ and $\mathbf{b}$ $\mathrm{Pd} / \mathrm{SSZ}-13(\mathrm{SAR}=12$ and 24$)$, while $\mathrm{Pd} / \mathrm{Ce} / \mathrm{Al}_{2} \mathrm{O}_{3}$ is base case reference catalyst. Prior to the TPO experiment, the samples were reduced for $30 \mathrm{~min}$ under $1 \% \mathrm{H}_{2}$ in $\mathrm{Ar}$ at $500{ }^{\circ} \mathrm{C}$
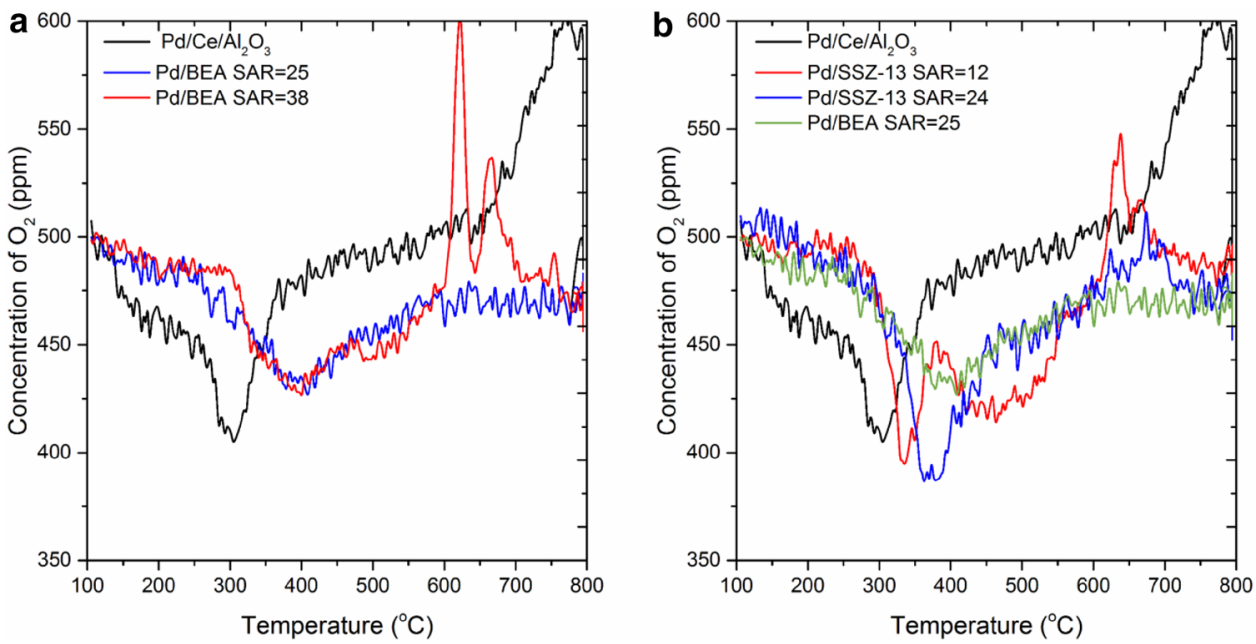
BEA $(\mathrm{SAR}=25)$ is compared with $\mathrm{Pd} / \mathrm{SSZ}-13(\mathrm{SAR}=24)$, and it is clear that $\mathrm{Pd} / \mathrm{SSZ}-13$ has larger oxygen uptake. For the lowest SAR, Pd/SSZ-13 (SAR = 12) two clear adsorption peaks are observed at 338 and ca $475{ }^{\circ} \mathrm{C}$, which indicate that different palladium species are available that are being oxidized. Moreover, the $\mathrm{O}_{2}$ release temperature for $\mathrm{Pd} / \mathrm{BEA}$ $(\mathrm{SAR}=38)$ and $\mathrm{Pd} / \mathrm{SSZ}-13$ (SAR $=12)$ are both lower compared to $\mathrm{Pd} / \mathrm{Ce} / \mathrm{Al}_{2} \mathrm{O}_{3}$, indicating that some of the oxygen on these catalyst are loosely bound. However, the desorbed amount is much lower for the $\mathrm{Pd} /$ zeolites than $\mathrm{Pd} / \mathrm{Ce} / \mathrm{Al}_{2} \mathrm{O}_{3}$, showing that the majority of the oxygen binds strongly.

XPS analysis was performed in order to examine the Pd oxidation states in the Pd/zeolite samples. The existence of $\mathrm{Pd}$ (II) over Pd/SSZ-13 and Pd/BEA catalysts (Fig. 5a, b) is revealed by XPS measurement of PdO sample used as reference and is presented in the lower panels in Fig. 5a, b. The peak positions for $\mathrm{Pd}(\mathrm{II})$ from $\mathrm{PdO}$ sample located at $337 \mathrm{eV}\left(3 \mathrm{~d}_{5 / 2}\right)$ and $342.4 \mathrm{eV}\left(3 \mathrm{~d}_{3 / 2}\right)$ were taken as the basis for deconvolution of XPS spectra. The values for Pd(IV) taken from the work of Zeng et al. [15] at $338.9 \mathrm{eV}\left(3 \mathrm{~d}_{5 / 2}\right)$ and $344.3 \mathrm{eV}\left(3 \mathrm{~d}_{3 / 2}\right)$, together with $\mathrm{Pd}(\mathrm{II})$ were used for deconvolution of experimental spectra presented in Fig. 5 with dashed red line. The calculated percentages of Pd(II) and $\mathrm{Pd}(\mathrm{IV})$ from spectra deconvolution reveal that $\mathrm{Pd}(\mathrm{II})$ dominate in all samples, which is also seen by comparing the spectras from the catalysts with the reference material. Both $\mathrm{Pd} / \mathrm{BEA}$ samples, as well as Pd/SSZ-13 (SAR =12) show similar amount of $\mathrm{Pd}(\mathrm{IV})$, between 25 and $32 \%$. The $\mathrm{Pd} /$ SSZ-13(SAR = 24), shows higher amount of Pd(VI) (49\%), but it should be noted that there are some uncertainties in the deconvolution due to low Pd signal in XPS, because of low Pd amount.

\subsection{NO Adsorption Using In-situ DRIFT Spectroscopy}

In order to further characterize the Pd species NO DRIFTS experiments were conducted. The DRIFTS spectra when adding $\mathrm{NO}$ to $\mathrm{O}_{2}$ and $\mathrm{H}_{2} \mathrm{O}$ gas mixture over $\mathrm{Pd} / \mathrm{Ce} / \mathrm{Al}_{2} \mathrm{O}_{3}$ are presented in Fig. 6 . The large bands between 1200 and $1600 \mathrm{~cm}^{-1}$ can be associated with different $\mathrm{NO}$ based species, such as: bridged nitrates at 1614 and $1232 \mathrm{~cm}^{-1}$ (1606 and $1249 \mathrm{~cm}^{-1}$ [30]), bidentate nitrates at $1545 \mathrm{~cm}^{-1}$ (1530-1540 $\left.\mathrm{cm}^{-1}[31]\right)$, bulk/ionic nitrates at $1417 \mathrm{~cm}^{-1}$

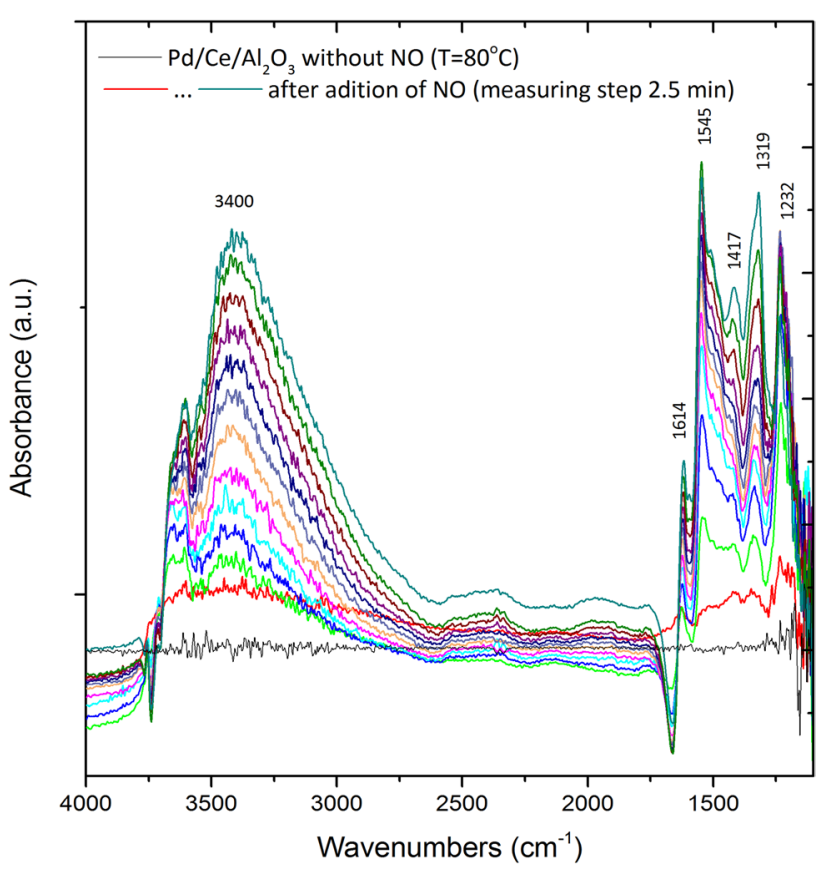

Fig. 6 DRIFTS spectra of $\mathrm{Pd} / \mathrm{Ce} / \mathrm{Al}_{2} \mathrm{O}_{3}$ recorded at $80{ }^{\circ} \mathrm{C}$ after exposure to $\mathrm{NO}$ with $\mathrm{O}_{2}$ and $\mathrm{H}_{2} \mathrm{O}$ in the gas mixture
Fig. 5 Pd 3d XPS spectra of the fresh a Pd/SSZ-13 with $\mathrm{SAR}=12$ and $\mathrm{SAR}=24, \mathbf{b}$ $\mathrm{Pd} / \mathrm{BEA}$ with $\mathrm{SAR}=38$ and $\mathrm{SAR}=300$
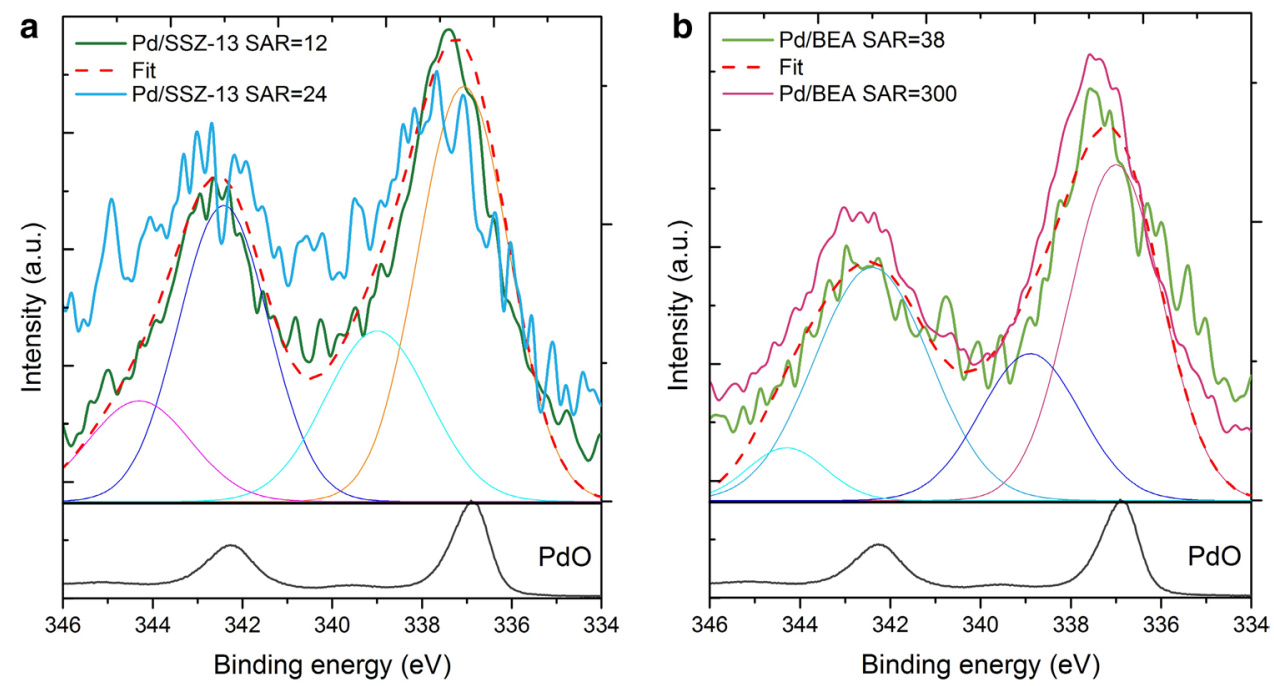
(1420 $\mathrm{cm}^{-1}$ [32]) and bridged nitrites at $1319 \mathrm{~cm}^{-1}$ $\left(1320 \mathrm{~cm}^{-1}\right.$ [30]). The identification of adsorption sites is problematic because $\mathrm{Al}_{2} \mathrm{O}_{3}, \mathrm{Pd} / \mathrm{Al}_{2} \mathrm{O}_{3}$ and $\mathrm{Pd} / \mathrm{CeO}_{2}$ show bands in the same region [32-34]. The appearance of the broad band at higher frequencies, more specifically in the region of $2500-3800 \mathrm{~cm}^{-1}$ are associated various hydroxyl species [35]. Even though the catalyst was exposed for several hours to water and $\mathrm{O}_{2}$, prior to adding $\mathrm{NO}$, the hydroxyl groups continued to grow.

Figure 7 shows DRIFT spectra collected during NO adsorption on $\mathrm{Pd} / \mathrm{SSZ}-13$ with various SARs in the presence of $\mathrm{O}_{2}$ and $\mathrm{H}_{2} \mathrm{O}$ at $80{ }^{\circ} \mathrm{C}$ in the range of $1500-4000 \mathrm{~cm}^{-1}$. The highest peaks are observed at 1818 and $1817 \mathrm{~cm}^{-1}$, respectively (Fig. 7a, b). Moreover, a band with lower intensity is found at $1871-1872 \mathrm{~cm}^{-1}$. According to Chakarova et al. [36], bands at 1881 and $1839 \mathrm{~cm}^{-1}$, can be associated with nitrosyl complexes on palladium cations in $\mathrm{Pd} /$ ZSM-5, where $1881 \mathrm{~cm}^{-1}$ is assigned to $\mathrm{Pd}^{2+}-\mathrm{NO}$ nitrosyls and $1839 \mathrm{~cm}^{-1}$ to $\mathrm{Pd}^{2+}\left(\mathrm{H}_{2} \mathrm{O}\right)(\mathrm{NO})$. Based on these literature results, we assign our band at $1818 \mathrm{~cm}^{-1}$ to $\mathrm{Pd}^{2+}\left(\mathrm{H}_{2} \mathrm{O}\right)(\mathrm{NO})$ nitrosyls and at $1871 \mathrm{~cm}^{-1}$ to $\mathrm{Pd}^{2+}-\mathrm{NO}$ nitrosyls, respectively. These results are consistent with the work by Ryou et al. [22] that studied NO adsorption on Pd/SSZ-13 and found peaks at $1800 \mathrm{~cm}^{-1}$ with a shoulder at $1860 \mathrm{~cm}^{-1}$, that they assigned to nitrosyl complexes on ionic Pd species. Moreover, according to Hess et al. [37], there are NO dimer species formed on $\operatorname{Pd}(111)$ giving a band at $1779 \mathrm{~cm}^{-1}$. We observe bands in this region at 1724 and $1745 \mathrm{~cm}^{-1}$ for the two Pd/SSZ-13 samples and we suggest that these are originating from $\mathrm{NO}$ dimers on palladium. A possible reason for the differences observed between our study and the work by Hess et al. [37] is that large part of our palladium is in ion-exchanged positions and Pd particles while in the other work, $\operatorname{Pd}(111)$ surface was studied.

One broad area, with two overlapping broad bands were found in the region $2000-2400 \mathrm{~cm}^{-1}$, for example for $\mathrm{Pd} /$ SSZ-13(SAR $=24)$ at 2112 and $2281 \mathrm{~cm}^{-1}$. The band
$2112 \mathrm{~cm}^{-1}$ is assigned to nitrosonium ions adsorbed onto different cationic positions in the zeolite framework [38-40]. Chen et al. [13] also observed a peak in this area for $\mathrm{Pd} /$ CHA in a similar region $\left(2151 \mathrm{~cm}^{-1}\right)$ which they assign to $\mathrm{NO}^{+}$on Brønsted acid sites. However, this was in dry conditions, and when they added water this band disappeared, showing the instabilities of NO species associated directly with the zeolite structure. In our study the NO species associated with the zeolite structure grew also in the presence of water and the difference could be due to that we used lower water concentration and lower temperature compared to the study by Chen et al. [13]. Interestingly, we have an additional band at higher frequency, $2281 \mathrm{~cm}^{-1}$, which is further shifted to $2433-2446 \mathrm{~cm}^{-1}$ for Pd/BEA (see Fig. 8). This band was not observed when exposing H/ZSM-5 to NO and $\mathrm{O}_{2}$, only a band at $2128 \mathrm{~cm}^{-1}$ was found [41]. Thus, it is not likely that this band is associated with $\mathrm{NO}$ species on the zeolite. Moreover, this band was not available for $\mathrm{Pd} / \mathrm{Ce} /$ $\mathrm{Al}_{2} \mathrm{O}_{3}$ (see Fig. 6), thus it is not related to Pd particles. A possible explanation for this band could be nitrosyl species that are interacting with the zeolite in close contact with the palladium ions. Moreover, the shift of this band to higher wave lengths for Pd/BEA is in accordance with the work by Chen et al. [13], where they found that some bands shifted upwards when increasing the pore-size of the zeolite.

During the first minutes of adsorption, the band associated with nitrosyls on ionic palladium (1817 and $1871 \mathrm{~cm}^{-1}$ ) increased. Interestingly, after 9 min the peaks at ca 1872 and $1818 \mathrm{~cm}^{-1}$ start to reduce while the wide absorption bands in the region $2000-2500 \mathrm{~cm}^{-1}$ is becoming more visible, both for Pd/SSZ-13 and Pd/BEA. For example, in the case of $\mathrm{Pd} /$ SSZ-13 $(\mathrm{SAR}=24)$ there is a distinctive increase in the two bands at 2281 and $2112 \mathrm{~cm}^{-1}$ with prolonged NO exposure. These results suggests that after building up $\mathrm{Pd}^{2+}-\mathrm{NO}$ species there starts to become more interaction with $\mathrm{NO}$ in the interface between zeolite and palladium atoms.
Fig. 7 DRIFTS spectra obtained during a Pd/SSZ-13 $(\mathrm{SAR}=12)$ and $\mathbf{b}$ Pd/SSZ-13 (SAR = 24) exposure to $\mathrm{NO}$ under $\mathrm{O}_{2}$ and $\mathrm{H}_{2} \mathrm{O}$ at $80{ }^{\circ} \mathrm{C}$
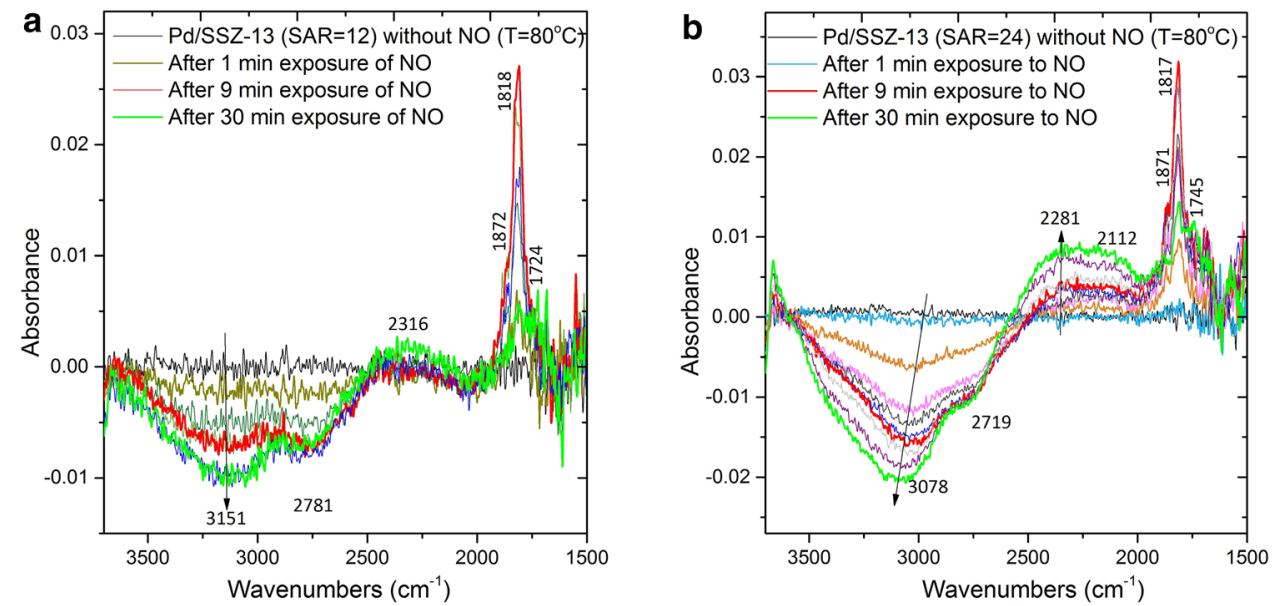
Fig. 8 NO DRIFTS spectra of $\mathbf{a}$ $\mathrm{Pd} / \mathrm{BEA}(\mathrm{SAR}=38)$ and $\mathbf{b} \mathrm{Pd} /$ BEA $($ SAR $=300)$

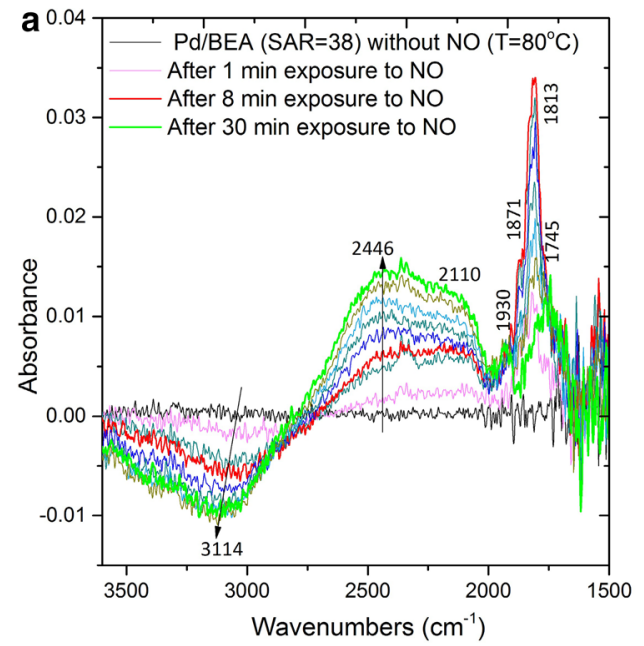

Simultaneously as the $\mathrm{NO}$ was stored, the $\mathrm{OH}$-groups (2500-3800 $\mathrm{cm}^{-1}$ ) were removed. The build-up of hydroxyl groups and water adsorption on palladium is found in many studies and is a large problem for methane oxidation over Pd containing catalysts [42]. Fully hydrated a palladium ion can coordinate up to four water molecules [43]. It is well known that there are $\mathrm{OH}$ groups charge balancing the copper species ion-exchanged in $\mathrm{Cu} / \mathrm{SSZ}-13$, where $\mathrm{ZCu}{ }^{\mathrm{II}} \mathrm{OH}$ are formed (located in the 8MRs under non-reactive conditions [44]). In a similar way we propose that $\mathrm{OH}$ groups are also charge balancing the Pd species that are in ion-exchanged positions into the zeolite and there could also be water species adsorbed to the Pd sites. During NO adsorption some of these water species are pushed out, resulting in negative bands for the OH-groups. The XPS results (Fig. 4) showed large amount of $\mathrm{Pd}(\mathrm{II})$, which could originate from ionexchanged palladium, which is in line with NO DRIFTS, where a clear band at $1818 \mathrm{~cm}^{-1}$ is observed due to nitrosyls on the Pd ions. This band in DRIFTS was not present for the $\mathrm{Pd} / \mathrm{Ce} / \mathrm{Al}_{2} \mathrm{O}_{3}$ showing that it is not occurring for $\mathrm{NO}$ adsorption on $\mathrm{Pd}$ particles.

There are quite large differences observed for NO adsorption on Pd/SSZ-13 with different SAR. For the Pd/SSZ-13 $(\mathrm{SAR}=24)$ there is larger $\mathrm{OH}$ removal and in addition more NO species are associated with the zeolite structure and the interface between the structure and palladium. For the sample with low $\mathrm{Si}$ to $\mathrm{Al}$ ratio (SAR=12, Fig. 7a) more $\mathrm{Pd}$ can bind to two $\mathrm{Al}$, while for higher SAR there is less $\mathrm{Al}$ available and there will be a larger fraction of Pd binding to only one $\mathrm{Al}$ and charge balancing with $\mathrm{OH}$ groups. This results in that more $\mathrm{OH}$-groups are removed for the sample with $\mathrm{SAR}=24$, which is clearly observed when comparing Fig. 7a, b.

The same experiment was conducted over Pd/BEA zeolites with SAR 38 and 300 and the results are shown in Fig. 8 a, b, respectively. Pd/BEA (SAR = 38), exhibit many similarities with Pd/SSZ-13 samples, where the nitrosyls on Pd ions are growing, while the hydroxyl species are being removed. The peak at $2000-2200 \mathrm{~cm}^{-1}$ which is assigned to nitrosyls $\left(\mathrm{NO}^{+}\right)$adsorbed on metal cations of the support [38-40] is growing more for Pd/BEA $(\mathrm{SAR}=38)$ compared to Pd/SSZ-13 (SAR = 24) and finally Pd/SSZ-13 $(\mathrm{SAR}=12)$ exhibit the smallest amount of this specie. Thus, it is clear that lowering the amount of $\mathrm{Al}$ in the sample increases this specie. In the same way as for Pd/SSZ-13, the peaks at ca 1813 and $1871 \mathrm{~cm}^{-1}$, is first growing during first 6-8 min and thereafter decreasing, while the peaks at ca 2110 and $2446 \mathrm{~cm}^{-1}$ continues to grow. These results suggests that NO adsorbed on the ion-exchanged Pd sites, are transferred to also interact with the zeolite. When examining the results for Pd/BEA ( $S A R=300$ ), see Fig. $8 b$, there are quite large differences compared to Pd/BEA $(\mathrm{SAR}=38)$ and the $\mathrm{Pd} /$ SSZ-13 samples. The main difference is that the peak at $1816 \mathrm{~cm}^{-1}$ is significantly smaller. This means that there is only a small amount of nitrosyl species on the ionic Pd, and this is reasonable since there are very few ionic exchange positions available for the palladium due to very small amount of $\mathrm{Al}$.

\subsection{NO TPD Experiments in Various Gas Mixtures}

An important characteristic of PNA materials is that they should be able to adsorb and store large amount of $\mathrm{NO}_{x}$ at low temperature and release it preferably between 200-300 ${ }^{\circ} \mathrm{C}$. This is investigated in this study by different TPD experiments by varying the feed composition. Figure 9 shows the results of the $\mathrm{NO}_{x}$ trapping at $80{ }^{\circ} \mathrm{C}$ followed by desorption phase with temperature ramp until $400{ }^{\circ} \mathrm{C}$ for $\mathrm{Pd} / \mathrm{Ce} / \mathrm{Al}_{2} \mathrm{O}_{3}$ catalyst. The NO concentration rapidly increases reaching the inlet $\mathrm{NO}$ concentration when $\mathrm{H}_{2} \mathrm{O}$ is added to the $\left(\mathrm{NO}+\mathrm{O}_{2}\right)$ feed mixture (Fig. 9b) compared to the $\left(\mathrm{NO}+\mathrm{O}_{2}\right)$ TPD (Fig. 9a). Thus, it is clear that water inhibits the storage 
Fig. 9 TPD 1, 2, 3 and 4 (abbreviated in this study) over $\mathrm{Pd} / \mathrm{Ce} / \mathrm{Al}_{2} \mathrm{O}_{3}$ catalyst using a $\mathrm{NO}+\mathrm{O}_{2}, \mathbf{b} \mathrm{NO}+\mathrm{O}_{2}+\mathrm{H}_{2} \mathrm{O}, \mathbf{c}$ $\mathrm{NO}+\mathrm{O}_{2}+\mathrm{H}_{2} \mathrm{O}+\mathrm{CO}_{2}$ and $\mathbf{d}$ $\mathrm{NO}+\mathrm{O}_{2}+\mathrm{H}_{2} \mathrm{O}+\mathrm{CO}_{2}+\mathrm{CO}$. For experimental details see Table 2


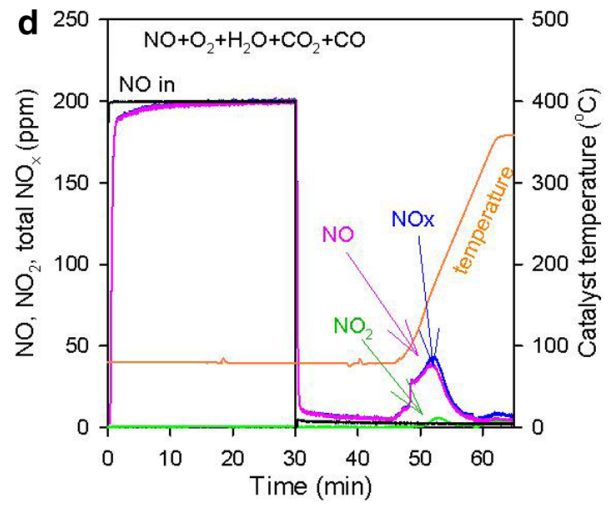

and this negative water effect was also found by Zheng et al. [15] over Pd/zeolites. The addition of $\mathrm{CO}_{2}$ also affects the storage negatively (see Fig. 9c). Moreover, there are some $\mathrm{NO}_{2}$ detected in the reactor outlet during desorption. However, no $\mathrm{NO}_{2}$ is visible during the adsorption phase. Thus we suggest that there are some nitrates formed that when decomposing forms $\mathrm{NO}_{2}$. However, when $\mathrm{CO}$ was present during the storage, there was almost no $\mathrm{NO}_{2}$ observed during the TPD (Fig. 9d), showing the inhibition effect of $\mathrm{CO}$ on the nitrate formation. Moreover, during desorption for the dry TPD experiment, three peaks are observed which is not the case for the $\mathrm{NO}+\mathrm{O}_{2}+\mathrm{H}_{2} \mathrm{O}+\mathrm{CO}_{2}$ experiment. For example, the low temperature shoulder is not found in the presence of water and this could be that water disables the formation of loosely bound nitrates/nitrates. For the $\mathrm{NO}+\mathrm{O}_{2}+\mathrm{H}_{2} \mathrm{O}$ TPD there is one major peak, but with small sudden increase in the concentration, which likely originates from water fluctuation.

The $\mathrm{NO}_{x}$ storage profiles of Pd/SSZ-13 $(\mathrm{SAR}=12)$ are presented in Fig. 10. Same adsorption-desorption event (see Fig. 9) was performed. The storage in dry conditions is significantly larger compared to in the presence of water also for this sample, in accordance with literature [15]. In addition, the $\mathrm{CO}$ addition increased the storage significantly (doubled the $\mathrm{NO}_{x}$ in the TPD), which is in line with the work by $\mathrm{Vu}$ et al. over Pd/BEA [17]. DRIFT studies indicate that $\mathrm{CO}$ addition lowers the oxidation state of the palladium, which results in that $\mathrm{NO}_{x}$ can bind more strongly due to $\pi$-back donation from Pd when the metal gets more electrons [17].

In order to easier facilitate comparison of the effect of different gases, the $\mathrm{NO}_{x}$ release profiles for $\mathrm{Pd} / \mathrm{Ce} / \mathrm{Al}_{2} \mathrm{O}_{3}$ and different $\mathrm{Pd}$-zeolites are depicted in Fig. 11, after adsorption experiments at $80{ }^{\circ} \mathrm{C}$ in the presence of water. The addition of $\mathrm{CO}_{2}$ has an important impact on Ce (Fig. 11a), where it decreases the storage and release. However, a similar trend was not found for BEA and SSZ-13-based materials (Fig. $11 \mathrm{~b}, \mathrm{c}$ ), where the addition of $\mathrm{CO}_{2}$ did not give any effect. The formation of cerium carbonates [45] in the presence of $\mathrm{CO}_{2}$, could be the reason for the negative effect of $\mathrm{CO}_{2}$ on $\mathrm{Pd} / \mathrm{Ce} / \mathrm{Al}_{2} \mathrm{O}_{3}$. As an example, the desorbed amount of $\mathrm{NO}_{x}$ for Pd/SSZ-13 (SAR = 12) was determined and we found $103 \mu \mathrm{mol}$ of $\mathrm{NO}_{x}$ for the dry case, while for $\mathrm{NO}+\mathrm{O}_{2}+\mathrm{H}_{2} \mathrm{O}$ and $\mathrm{NO}+\mathrm{O}_{2}+\mathrm{H}_{2} \mathrm{O}+\mathrm{CO}_{2}, 6.8$ and $7.0 \mu \mathrm{mol}$ of $\mathrm{NO}_{x}$ were observed, which clearly shows the huge negative impact of water, while no effect of $\mathrm{CO}_{2}$ addition.

Furthermore, the results presented in Fig. 11 show that the addition of $\mathrm{CO}$ influences the $\mathrm{NO}_{x}$ storage and desorption. $\mathrm{CO}$ is an important component since the PNA likely will be the first component in the aftertreatment system, and there will therefore be $\mathrm{CO}$ present during most conditions. $\mathrm{CO}$ has earlier found to be beneficial for NO trapping for $\mathrm{Pd} / \mathrm{BEA}$ [17]. Interestingly, the addition of $\mathrm{CO}$ inhibits the $\mathrm{NO}_{x}$ storage over $\mathrm{Pd} / \mathrm{Ce} / \mathrm{Al}_{2} \mathrm{O}_{3}$ sample (Fig. 11a), whereas 
Fig. 10 TPD 1, 2, 3 and 4 over $\mathrm{Pd} / \mathrm{SSZ}-13(\mathrm{SAR}=12)$ using a $\mathrm{NO}+\mathrm{O}_{2}, \mathbf{b ~ N O}+\mathrm{O}_{2}+\mathrm{H}_{2} \mathrm{O}$, c $\mathrm{NO}+\mathrm{O}_{2}+\mathrm{H}_{2} \mathrm{O}+\mathrm{CO}_{2}$ and $\mathbf{d}$ $\mathrm{NO}+\mathrm{O}_{2}+\mathrm{H}_{2} \mathrm{O}+\mathrm{CO}_{2}+\mathrm{CO}$. For experimental details see Table 2
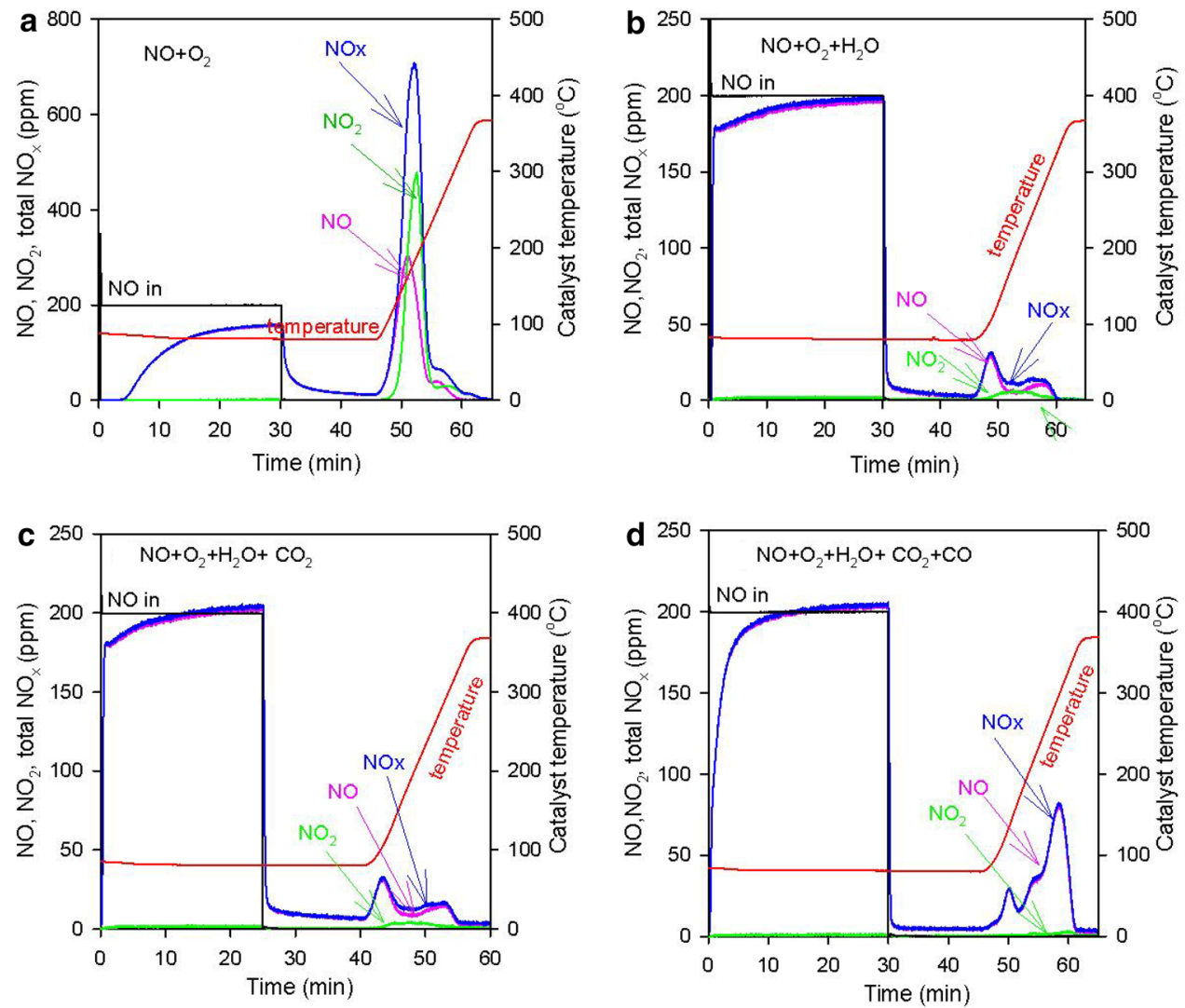

enhanced $\mathrm{NO}_{x}$ storage over the Pd-zeolites (Fig. 11b, c) were observed. For Pd/SSZ-13 (SAR $=12$ ), the $\mathrm{NO}_{x}$ desorbed was $15.4 \mu \mathrm{mol}$, i.e. there is more than twice the amount of stored $\mathrm{NO}_{x}$ (if assuming all $\mathrm{NO}_{x}$ are released) in the presence of $\mathrm{CO}$. This corresponds to $0.22 \mathrm{NO}$ per palladium. Moreover, the storage was much more enhanced over the Pd/SSZ-13-catalyst than Pd/BEA. The presence of CO resulted in a shift in desorption temperature toward higher temperatures over the $\mathrm{Pd} /$ zeolites and now a large amount of $\mathrm{NO}_{x}$ is released in the optimum window (ca $200-300^{\circ} \mathrm{C}$ ). It should be noted that there are multiple desorption peaks for the Pd/zeolites (Fig. 11b-d), while only one for the Pd/Ce/ $\mathrm{Al}_{2} \mathrm{O}_{3}$ sample. Multiple peaks were also found by $\mathrm{Vu}$ et al. [17], and using CO DRIFT experiments they concluded that there are both multiple Pd states, as well as multiple types of binding sites. This could explain that we observe multiple peaks for the $\mathrm{Pd} / \mathrm{zeolites}$.

Comparing similar $\mathrm{Si}$ to $\mathrm{Al}$ ratio (Fig. $11 \mathrm{c}, \mathrm{d}$ ), the effect of support (i.e. SSZ-13 and BEA) is clearly emphasized. There is large differences between the supports. For the experiments in the presence of $\mathrm{NO}+\mathrm{O}_{2}+\mathrm{H}_{2} \mathrm{O}$ and $\mathrm{NO}+\mathrm{O}_{2}+\mathrm{H}_{2} \mathrm{O}+\mathrm{CO}_{2}$ there are two peaks at low and medium temperature and a high temperature shoulder for $\mathrm{Pd} /$ BEA (see Fig. 11b, d). However, for the Pd/SSZ-13 catalyst there is only two peaks present at low and high temperature. Interestingly, when adding $\mathrm{CO}$ during the storage especially the high temperature peak is enhanced, and for Pd/BEA the shoulder at high temperature is now the dominating peak. Interestingly, the $\mathrm{CO}$ has significantly larger effect on the $\mathrm{Pd} /$ SSZ-13 ( $\mathrm{SAR}=24)$ compared to Pd/BEA ( $\mathrm{SAR}=25)$, where the $\mathrm{NO}_{x}$ desorbed is a factor of 3.6 larger for Pd/SSZ-13.

The effect of $\mathrm{Si}$ to $\mathrm{Al}$ ratio for $\mathrm{Pd} / \mathrm{BEA}$ in the absence/ presence of $\mathrm{CO}$ in $\left(\mathrm{NO}+\mathrm{O}_{2}+\mathrm{H}_{2} \mathrm{O}+\mathrm{CO}_{2}\right)$ mixture is studied and the results are presented in Fig. 12. Without the presence of CO, the Pd/BEA (see Fig. 12a) releases the $\mathrm{NO}_{x}$ in two desorption peaks around 100 and $180^{\circ} \mathrm{C}$, and an additional shoulder around $275^{\circ} \mathrm{C}$ for the Pd/BEA $(\mathrm{SAR}=25)$. Moreover, the low temperature peak is dominating for the $\mathrm{Pd} /$ BEA (SAR $=38)$, but the Pd/BEA ( $\mathrm{SAR}=300)$ stores less and have the main desorption peak at ca $180^{\circ} \mathrm{C}$. A possible reason for the poor PNA capacity of Pd/BEA $(\mathrm{SAR}=300)$ is the lack of ion-exchanged Pd sites.

The addition of $\mathrm{CO}$ results in a high temperature desorption peak for $\mathrm{Pd} / \mathrm{BEA}(\mathrm{SAR}=25$ and $\mathrm{SAR}=38$ ), see Fig. 12b, as previously observed in literature for Pd/BEA [17]. This is due to that $\mathrm{CO}$ reduces the palladium and forms metallic $\mathrm{Pd}$, "naked" $\mathrm{Pd}^{2+}$, and $\mathrm{Pd}^{+}$sites [15], where $\mathrm{NO}$ adsorption with higher binding energies occurs. Interestingly, there is no high temperature desorption peak found for $\mathrm{Pd} / \mathrm{BEA}(\mathrm{SAR}=300)$, when the adsorption was conducted in the presence of $\mathrm{CO}$ (see Fig. 12b). The reason for this is also, as discussed in previous paragraph, that there is very 
Fig. $11 \mathrm{NO}_{x}$ desorption curves for $\left(\mathrm{NO}+\mathrm{O}_{2}+\mathrm{H}_{2} \mathrm{O}\right)$ TPD, denoted TPD2,

$\left(\mathrm{NO}+\mathrm{O}_{2}+\mathrm{H}_{2} \mathrm{O}+\mathrm{CO}_{2}\right)$

TPD as TPD3 and

$\left(\mathrm{NO}+\mathrm{O}_{2}+\mathrm{H}_{2} \mathrm{O}+\mathrm{CO}_{2}+\mathrm{CO}\right)$

TPD as TPD4 over a Pd/Ce/

$\mathrm{Al}_{2} \mathrm{O}_{3}, \mathbf{b} \mathrm{Pd} / \mathrm{BEA}(\mathrm{SAR}=38)$, c Pd/SSZ-13 (SAR = 24) and d Pd/BEA $(\mathrm{SAR}=25)$. For experimental details see Table 2

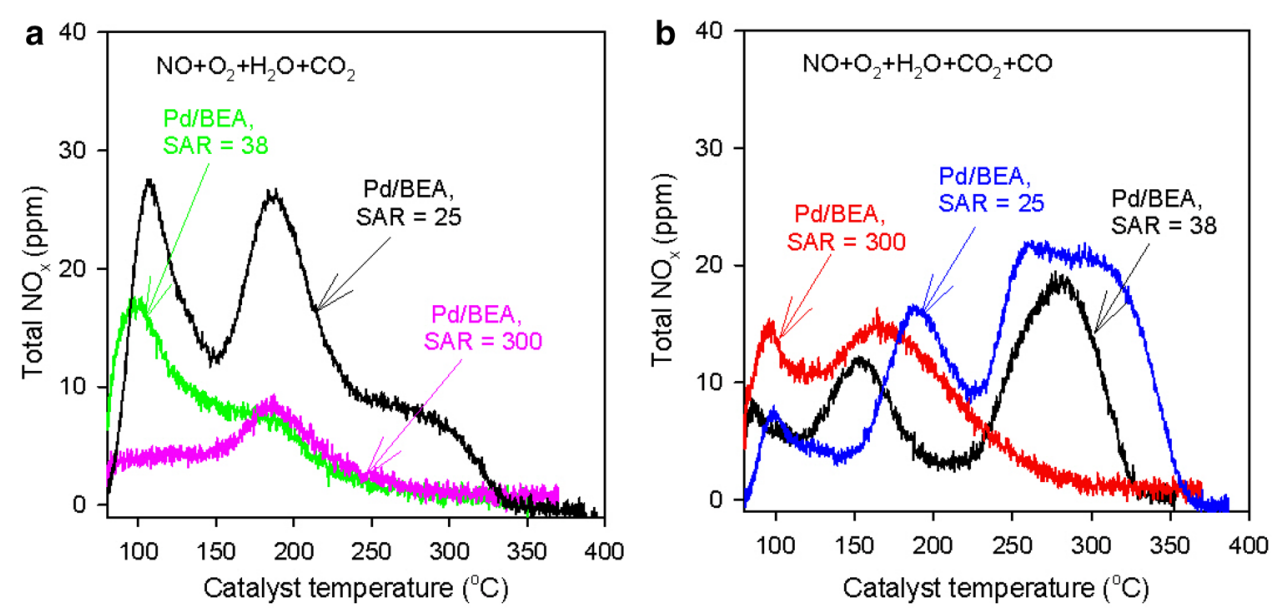

Fig. $12 \mathrm{NO}_{x}$ desorption profiles of Pd/BEA (SAR $=25)$, Pd/ BEA $(\mathrm{SAR}=38)$ and $\mathrm{Pd} /$ BEA $(\mathrm{SAR}=300)$, during a $\mathrm{NO}+\mathrm{O}_{2}+\mathrm{H}_{2} \mathrm{O}+\mathrm{CO}_{2}$ TPD and b $\mathrm{NO}+\mathrm{O}_{2}+\mathrm{H}_{2} \mathrm{O}+\mathrm{CO}_{2}+\mathrm{CO}$ TPD experiments. For experimental details see Table 2 little ion-exchanged Pd available in this sample, as evident from the NO DRIFTS data (see Fig. 8b) and Pd mostly is in the form of Pd particles. For $\mathrm{Pd} / \mathrm{Ce} / \mathrm{Al}_{2} \mathrm{O}_{3}$, surprisingly, the $\mathrm{CO}$ addition was even negative (see Fig. 11a). To conclude, $\mathrm{CO}$ addition is beneficial when there is $\mathrm{Pd}$ available in ionexchanged positions, which is the case for $\mathrm{Pd} /$ zeolites with low and medium SAR, and this result in Pd reduction and more stable $\mathrm{NO}_{x}$ species. However, for Pd/BEA with high $\mathrm{SAR}$ or $\mathrm{Pd} / \mathrm{Ce} / \mathrm{Al}_{2} \mathrm{O}_{3}$, the $\mathrm{CO}$ addition is not favorable.

The corresponding comparison for the $\mathrm{NO}_{x}$ desorption curves using Pd/SSZ-13 with different SAR are shown in Fig. 13. The results for Pd/SSZ-13(SAR =12) and Pd/ 
Fig. $13 \mathrm{NO}_{x}$ desorption curves of Pd/SSZ-13 $(\mathrm{SAR}=12)$ and $\mathrm{Pd} / \mathrm{SSZ}-13(\mathrm{SAR}=24)$ during a $\mathrm{NO}+\mathrm{O}_{2}+\mathrm{H}_{2} \mathrm{O}+\mathrm{CO}_{2}$ TPD and b $\mathrm{NO}+\mathrm{O}_{2}+\mathrm{H}_{2} \mathrm{O}+\mathrm{CO}_{2}+\mathrm{CO}$ TPD experiments. For experimental details see Table 2



SSZ-13(SAR =24) is quite similar and this shows that there needs to be larger variations in the SAR ratio in order to see larger effects.

\section{Conclusions}

$\mathrm{Pd} / \mathrm{BEA}$ and Pd/SSZ-13 with different SARs and Pd/Ce/ $\mathrm{Al}_{2} \mathrm{O}_{3}$ as a base catalyst were synthesized and investigated for potential PNA use. The catalysts were characterized by BET, XRD, XPS, TPO, STEM and ICP-SFMS. The adsorbed NO species were examined using in-situ DRIFT spectroscopy and the adsorption/desorption characteristics were investigated using NO TPD experiments in various gas mixtures.

The TPO results showed that it required higher temperature to oxidize the $\mathrm{Pd} /$ zeolites than $\mathrm{Pd} / \mathrm{Ce} / \mathrm{Al}_{2} \mathrm{O}_{3}$. Moreover, the STEM showed that the Pd particles for Pd/BEA $(\mathrm{SAR}=300)$ was significantly larger compared to the other zeolites with lower SAR for freshly calcined powder. However, after using the monoliths the Pd particles in Pd/BEA ( $\mathrm{SAR}=300$ ) were reduced in size. The XPS data showed that in general for the $\mathrm{Pd} /$ zeolites there was large amount of $\mathrm{Pd}(\mathrm{II})$ and smaller amount of Pd(IV).

DRIFT spectroscopy revealed that on $\mathrm{Pd} / \mathrm{Ce} / \mathrm{Al}_{2} \mathrm{O}_{3}$ the $\mathrm{NO}$ was mainly stored as nitrates and nitrites in the region of $1600-1200 \mathrm{~cm}^{-1}$. However, for the $\mathrm{Pd} /$ zeolites two peaks around $1800 \mathrm{~cm}^{-1}$ was found that relates to nitrosyl complexes on ionic Pd species. Moreover, a broad band in the region $2000-2500 \mathrm{~cm}^{-1}$ was observed, being more pronounced with increase in SARs. We assign these to nitrosyl species that interacts with zeolite structure, possibly in close connection with the Pd. In addition, hydroxyl species were found in the region $2500-3800 \mathrm{~cm}^{-1}$. The catalyst had been pre-treated in $\mathrm{H}_{2} \mathrm{O}$ and $\mathrm{O}_{2}$ for several hours, both at high temperature and at the adsorption temperature $\left(80^{\circ} \mathrm{C}\right)$. However, when starting to introduce the $\mathrm{NO}$, the $\mathrm{OH}$-bands continued to grow on the $\mathrm{Pd} / \mathrm{Ce} / \mathrm{Al}_{2} \mathrm{O}_{3}$ sample, while they clearly decreased for the $\mathrm{Pd} /$ zeolites. We suggest that the reason for this is that for the $\mathrm{Pd} /$ zeolites there are palladium in ion-exchanged positions in the zeolite which is charge balanced with $\mathrm{OH}$ groups and also that there are water species adsorbed on these Pd species. This explains why there is such a negative impact during NO TPD experiments when adding water, since water blocks the Pd sites. In order to adsorb NO, NO must push out water species and this is the reason for that the $\mathrm{OH}$-bands clearly decrease during $\mathrm{NO}$ adsorption over the Pd/zeolites.

Various NO TPD experiments were conducted and it was found that water significantly reduced the NO storage ability for all samples. Moreover, the addition of $\mathrm{CO}_{2}$ to the $\mathrm{NO}+\mathrm{O}_{2}+\mathrm{H}_{2} \mathrm{O}$ gas mixture decreased the storage on $\mathrm{Pd} / \mathrm{Ce} / \mathrm{Al}_{2} \mathrm{O}_{3}$ likely due to cerium carbonate formation, while it did not affect the $\mathrm{Pd} /$ zeolites. The addition of $\mathrm{CO}$ to $\mathrm{NO}+\mathrm{O}_{2}+\mathrm{H}_{2} \mathrm{O}+\mathrm{CO}_{2}$ resulted in interesting effects, where the effect differed if the palladium was in the form of $\mathrm{Pd}$ particles or in ion-exchanged positions and therefore also varied with $\mathrm{Si} / \mathrm{Al}$ ratio.

The effect of SARs of the zeolites samples on the NO adsorption/desorption ability was studied. In $\mathrm{NO}+\mathrm{O}_{2}+\mathrm{H}_{2} \mathrm{O}+\mathrm{CO}_{2} \mathrm{TPD}$, the $\mathrm{Pd} / \mathrm{BEA}$ samples released the $\mathrm{NO}_{x}$ at around 100 and $180{ }^{\circ} \mathrm{C}$, for $\mathrm{Pd} / \mathrm{BEA}(\mathrm{SAR}=38$ and 300). However, for the Pd/BEA (SAR = 38) the low temperature peak is dominating, while this peak is very small for Pd/BEA (SAR $=300)$ and this sample also stores very little. Both these desorption peaks occur at too low temperature, since the optimum release temperature is between 200 and $300{ }^{\circ} \mathrm{C}$. In addition, for Pd/BEA $(\mathrm{SAR}=25)$ an extra shoulder was observed at higher temperature. Interestingly, when adding $\mathrm{CO}$ during the adsorption phase, the stored $\mathrm{NO}_{x}$ species for $\mathrm{Pd} / \mathrm{BEA}$ ( $\mathrm{SAR}=25$ and 38 ) is much more stable and is released at about $280{ }^{\circ} \mathrm{C}$, but this peak is not existing for $\mathrm{Pd} / \mathrm{BEA}(\mathrm{SAR}=300)$. This peak does also not e xist either on the $\mathrm{Pd} / \mathrm{Ce} / \mathrm{Al}_{2} \mathrm{O}_{3}$ sample, where actually the $\mathrm{NO}$ storage 
is decreasing in the presence of $\mathrm{CO}$. These results show that if the $\mathrm{Pd}$ is mostly in the form of particles, like for $\mathrm{Pd} / \mathrm{BEA}$ $(\mathrm{SAR}=300)$ and $\mathrm{Pd} / \mathrm{Ce} / \mathrm{Al}_{2} \mathrm{O}_{3}$, the $\mathrm{CO}$ addition is not beneficial. But if $\mathrm{Pd}$ is in ion-exchanged positions in the zeolite, the $\mathrm{CO}$ addition is beneficial because it helps to reduce the Pd species, which facilitate NO storage with higher binding energy. For both Pd/SSZ-13 samples (SAR $=12$ and $\mathrm{SAR}=24$ ) there was a clear benefit of adding $\mathrm{CO}$ to the storage mixture, because also for these materials it increased the binding strength. Interestingly, the $\mathrm{CO}$ addition significantly increased the NO adsorption amount for Pd/SSZ-13, much more compared to the Pd/BEA. When comparing $\mathrm{Pd} /$ BEA (SAR $=25)$ with Pd/SSZ-13 $(\mathrm{SAR}=24)$ it is clear that the Pd/SSZ-13 forms more $\mathrm{NO}_{x}$ species with higher stability and this was especially the case in the presence of $\mathrm{CO}$.

Acknowledgements The funding from the Swedish Research Council (642-2014-5733) is acknowledged. This work was carried out at the Competence Centre for Catalysis and Chemical Engineering, Chalmers University of Technology. We acknowledge the help from Stefan Gustafsson, Division of Applied Physics at the Chalmers University of Technology for STEM measurements.

Open Access This article is distributed under the terms of the Creative Commons Attribution 4.0 International License (http://creativeco mmons.org/licenses/by/4.0/), which permits unrestricted use, distribution, and reproduction in any medium, provided you give appropriate credit to the original author(s) and the source, provide a link to the Creative Commons license, and indicate if changes were made.

\section{References}

1. Körfer T (2013) Potential of advanced, combined aftertreatment systems for light-duty diesel engines to meet upcoming EU and US emission regulation, SAE International

2. Roy S, Baiker A (2009) Chem Rev 109:4054-4091

3. Epling WS, Campbell LE, Yezerets A, Currier NW, Parks JE (2004) Catal Rev 46:163-245

4. Olsson L, Wijayanti K, Leistner K, Kumar A, Joshi SY, Kamasamudram K, Currier NW, Yezerets A (2016) Appl Catal B 183:394-406

5. Forzatti P, Nova I, Tronconi E (2010) Ind Eng Chem Res 49:10386-10391

6. Beale AM, Gao F, Lezcano-Gonzalez I, Peden CHF, Szanyi J (2015) ChemSocRev 44:7371-7405

7. Lundström A, Andersson B, Olsson L (2009) Chem Eng J 150:544-550

8. Jones S, Ji Y, Bueno-Lopez A, Song Y, Crocker M (2017) Emiss Control Sci Technol 3:59-72

9. Tamm S, Andonova S, Olsson L (2014) Catal Lett 144:674-684

10. Ji Y, Bai S, Crocker M (2015) Appl Catal B 170-171:283-292

11. Ren SX, Schmieg SJ, Koch CK, Qi GS, Li W (2015) Catal Today 258:378-385

12. Melville JE, B RJ, K O, P PR, Mountstevens EH (2012) Johnson Matthey Public Limited Company, Royston

13. Chen H-Y, Collier JE, Liu D, Mantarosie L, Durán-Martín D, Novák V, Rajaram RR, Thompsett D (2016) Catal Lett 146:1706-1711

14. Theis JR, Lambert CK (2015) Catal Today 258:367-377
15. Zheng Y, Kovarik L, Engelhard MH, Wang Y, Wang Y, Gao F, Szanyi J (2017) J Phys Chem C 121:15793-15803

16. Lee J, Ryou Y, Cho SJ, Lee H, Kim CH, Kim DH (2018) Appl Catal B 226:71-82

17. Vu A, Luo J, Li J, Epling WS (2017) Catal Lett 147:745-750

18. McEwen JS, Anggara T, Schneider WF, Kispersky VF, Miller JT, Delgass WN, Ribeiro FH (2012) Catal Today 184:129-144

19. Olsson L, Wijayanti K, Leistner K, Kumar A, Joshi SY, Kamasamudram K, Currier NW, Yezerets A (2015) Appl Catal B 174-175:212-224

20. Franchini CA, Cesar DV, Schmal M (2010) Catal Lett 137:45-54

21. Lim JB, Jo D, Hong SB (2017) Appl Catal B 219:155-162

22. Ryou Y, Lee J, Lee H, Kim CH, Kim DH (2017) Catal Today 297:53-59

23. Kamińska II, Lisovytskiy D, Casale S, Śrębowata A, Dzwigaj S (2017) Microporous Mesoporous Mater 237:65-73

24. Tidahy HL, Siffert S, Lamonier JF, Zhilinskaya EA, Aboukaïs A, Su BL, Canet X, Deweireld G, Frère M, Gireaudon JM, Leclercq G (2007) Characterisation of palladium supported on exchanged BEA and FAU zeolites for VOCs catalytic oxidation. In: Llewellyn PL, Rodriquez-Reinoso F, Rouqerol J, Seaton N (Eds.) Studies in surface science and catalysis. Elsevier, New York

25. Yamanaka N, Itakura M, Kiyozumi Y, Ide Y, Sadakane M, Sano T (2012) Microporous Mesoporous Mater 158:141-147

26. Wang Y, Chen J, Lei X, Ren Y, Wu J (2018) Adv Powder Technol 29:1112-1118

27. Higgins JB, LaPierre RB, Schlenker JL, Rohrman AC, Wood JD, Kerr GT, Rohrbaugh WJ (1988) Zeolites 8:446-452

28. Leistner K, Brüsewitz F, Wijayanti K, Kumar A, Kamasamudram K, Olsson L (2017) Energies 10:489

29. Sadokhina N, Smedler G, Nylén U, Olofsson M, Olsson L (2017) Appl Catal B 200:351-360

30. Westerberg B, Fridell E (2001) J Mol Catal 165:249-263

31. Theologides CP, Olympiou GG, Savva PG, Kapnisis K, Anayiotos A, Costa CN (2017) Appl Catal B 205:443-454

32. Nova I, Castoldi L, Lietti L, Tronconi E, Forzatti P, Prinetto F, Ghiotti G (2004) J Catal 222:377-388

33. Auvray X, Olsson L (2015) Appl Catal B 168:342

34. Ryou Y, Lee J, Lee H, Kim CH, Kim DH (2018) Catal Today 307:93-101

35. Ciuparu D, Perkins E, Pfefferle L (2004) Appl Catal A 263:145-153

36. Chakarova K, Ivanova E, Hadjiivanov K, Klissurski D, Knozinger H (2004) Phys Chem Chem Phys 006:3702-3709

37. Hess C, Ozensoy E, Yi CW, Goodman DW (2006) J Am Chem Soc 128:2988-2994

38. Hadjiivanov K, Saussey J, Freysz JL, Lavalley JC (1998) Catal Lett 52:103-108

39. Sedlmair C, Gil B, Seshan K, Jentys A, Lercher JA (2003) Phys Chem Chem Phys 5:1897-1905

40. Szanyi J, Hun Kwak J, Moline RA, Peden CHF (2003) Phys Chem Chem Phys 5:4045-4051

41. Lonyi F, Solt HE, Valyon J, Decolatti H, Gutierrez LB, Miro E (2010) Appl Catal B 100:133-142

42. Sadokhina N, Ghasempour F, Auvray X, Smedler G, Nylen U, Olofsson M, Olsson L (2017) Catal Lett 147:2360-2371

43. Akesson R, Pettersson LGM, Sandstrom M, Wahlgren U (1994) J Am Chem Soc 116:8691-8704

44. Paolucci C, Parekh AA, Khurana I, Di Iorio JR, Li H, Albarracin Caballero JD, Shih AJ, Anggara T, Delgass WN, Miller JT, Ribeiro FH, Gounder R, Schneider WF (2016) J Am Chem Soc 138:6028-6048

45. Chengwu Y, Fabian B, Jun C, Xiaojuan Y, Alexei N, Christof W (2017) ChemPhysChem 18:1874-1880 